\title{
Winter Wind Regimes over Israel Using Self-Organizing Maps $\mathscr{O}$
}

\author{
SigALIT BERKOVIC \\ Department of Mathematics, Israel Institute for Biological Research, Ness-Ziona, Israel
}

(Manuscript received 6 December 2016, in final form 26 June 2017)

\begin{abstract}
The aim of this study is to objectively define and automatically reconstruct surface wind regimes over Israel. Unlike other previous studies that subjectively examined case studies or applied the semiobjective synoptic classification (SOC), this study shows the ability of the method of self-organizing maps (SOM) to directly define well-known wind regimes at the synoptic hours $(0000,0600,1200$, and 1800 UTC) during the winter. This ability sets the groundwork for future automatic climatological analysis and applications. The investigation is performed by analyzing surface wind measurements from 53 Israel Meteorological Service stations. The relation between the synoptic variables and the wind regimes is revealed from the averages of ECMWF interim reanalysis (ERA-Interim) variables at each SOM wind regime. The inspection of wind regimes and their average pressure anomalies has shown that wind regimes relate to the gradient of the pressure anomalies rather than to the specific isobaric pattern. Two main wind regimes-strong western and strong eastern-are well known over this region. During daytime, SOM classification identifies these two regimes while SOC reveals only strong western regimes since SOC considers depth of the pressure gradients only in the case of low pressure centers. In accordance with previous studies, two main groups-winter low and high pressure centers and/or Red Sea troughs_-are related to the strong westerly or easterly wind regimes with low diurnal variability and high daily persistence. Regimes under weak pressure gradients have higher diurnal variability, relatively lower steadiness, and weaker speed. Their daily persistence is not necessarily low.
\end{abstract}

\section{Introduction}

The climate in Israel is a Mediterranean climate, with a hot and dry summer, transitional seasons, and rainy winter. During the summer, there is a single synoptic group (Persian trough) with a typical wind regime exhibiting diurnal veering according to the diurnal heating and topography (Skibin and Hod 1979; Ziv et al. 2004). During the winter and the transitional seasons, synoptic variability increases, and therefore a higher number of surface wind regimes are prevalent. Previous work (Berkovic 2016) presented the ability to use the frequent synoptic classes, defined by the semiobjective classification of Alpert et al. (2004), as a predictor of the hourly surface wind field over the Israeli coastal plain. Similar wind patterns were found under different synoptic classes, indicating that there is more than one

Supplemental information related to this paper is available at the Journals Online website: https://doi.org/10.1175/ JAMC-D-16-0381.s1.

Corresponding author: S. Berkovic, berkovic@iibr.gov.il synoptic group related to a single wind pattern. Many previous studies referred to a subjective or semiobjective synoptic classification, but there is a need for an automatic objective classification when studying the surface winds on an hourly time scale. The semiobjective synoptic classification is defined according to 1200 UTC data; therefore, one has to assume a constant synoptic class during that day. Synoptic classes at 0000 and 1200 UTC may differ, and therefore an automatic objective classification is needed when hourly surface winds are related to synoptic variables. An automatic algorithm will greatly facilitate the definition of wind regimes or synoptic classes, since a subjective analysis is highly tedious.

This work employs the objective nonlinear clustering technique known as self-organizing maps (SOM; Hewitson and Crane 2002; Liu et al. 2006; Liu and Weisberg 2011; Reusch et al. 2011; Sang et al. 2008; Sheridan and Lee 2011) to define wind regimes over Israel at the synoptic hours $(0000,0600,1200$, and 1800 UTC). The wind patterns are derived from surface wind measurements. The relation between surface wind patterns and synoptic conditions is clarified by calculating the averages of the synoptic variables according to the SOM classification. 
This method is separately applied at each synoptic hour. The synoptic variables were derived from ECMWF interim reanalysis (ERA-Interim) data.

SOM have been extensively used during the last 20 years to study meteorological variables, of which wind is a single example. Richardson et al. (2003) described the application of SOM to define surface wind regimes from satellite imagery data. Wind regimes over the Ross Ice Shelf in Antarctica were presented by Seefeldt and Cassano (2012) and also by Nigro and Cassano (2014), according to SOM analysis of data from the Weather Research and Forecasting Model (WRF). Jolly et al. (2016) presented an innovative way, aided by SOM analysis, to compare model and measurement results. Kalinić et al. (2015) used SOM to classify wind patterns over the Adriatic Sea using two mesoscale meteorological models, the hydrostatic Aire Limitée Adaptation Dynamique Développement International (ALADIN/ HR) model and the Advanced Research version of WRF (ARW), operational in the northern Adriatic Sea region. Surface current patterns from joint SOM analysis of high-frequency radar data and ALADIN/HR surface winds were presented by Mihanović et al. (2011). SOM classification may serve as a base for a forecasting tool (Sideratos and Hatziargyriou 2007; Liu et al. 2010; Gutierrez et al. 2005; Ismail et al. 2011).

Previous studies (Saaroni et al. 1998; Levy et al. 2008; Ziv and Yair 1994; Goldreich 2003) subjectively studied the surface flow over Israel. This study shows the ability of SOM to automatically reconstruct this knowledge. The main benefit of SOM is to advance beyond the traditional semiobjective methods. This information lays the groundwork for use of SOM instead of the old semiobjective methods for future studies. Possible future applications of this study are classification of air pollution patterns, pattern validation of meteorological models, or statistical downscaling of extreme wind events over the eastern Mediterranean (EM) Sea region.

Section 2 describes the method and the data. Section 3 briefly summarizes the frequent synoptic classes during winter according to the semiobjective classification (Alpert et al. 2004), and section 4 presents the SOM wind patterns and their relation to synoptic variables with references to previous works. Section 5 concludes the study.

\section{Data and method}

The surface wind regimes were derived from 10-min averages of surface wind measurements at 53 stations of the Israel Meteorological Service (IMS) from January 2006 to February 2012. The data were obtained online from the IMS (available, including measurement details, at https://ims.data.gov.il/). The measurements were performed $10 \mathrm{~m}$ above the ground by anemometers, mostly in rural areas. For each station there will be, in principle, 601 events at each synoptic hour from the winter months-December, January, and February (DJF) - during the studied period. The data were automatically monitored and registered as well as examined by a quality check.

The topography of the area and the locations of the stations are presented in Fig. 1. The description given here has been adapted from the article by Skibin and Hod (1979). The Mediterranean coastal plain is relatively flat, with its width varying from $\sim 50 \mathrm{~km}$ in the south of the map to $\sim 1 \mathrm{~km}$ near Haifa, Israel. Farther north, the width ranges from 2 to $12 \mathrm{~km}$. Parallel to the coast, a mountain ridge with peaks at $800-1200 \mathrm{~m}$ above mean sea level extends from north to south, interrupted by the Jezreel Valley to the east of Haifa. The mountains are the Judea and Samaria Mountains to the south and the Galilee Mountains to the north. Farther to the east, the Jordan Valley runs parallel to the ridge, having a depth between $70 \mathrm{~m}$ below mean sea level in the north and $400 \mathrm{~m}$ below mean sea level in the Dead Sea. The Jordan River flows from the Sea of Galilee to the Dead Sea. South of the Dead Sea lies the Arava Valley. A second mountain ridge resides to the east of the Jordan River. The IMS stations are situated in four major regions: 1 ) along the coast and the western slopes of the Judea and Samaria Mountains, 2) along the peaks of the Judea and Samaria Mountains, 3) the Galilee Mountains, and 4) the Jordan and Arava Valleys, including the Dead Sea area.

The average synoptic variables (temperature, specific humidity, horizontal and longitudinal wind components, and geopotential anomaly) at the chosen pressure levels-1000, 925, 850, and $500 \mathrm{hPa}$-were calculated from ERA-Interim data (http://apps.ecmwf.int/datasets/ data/interim-full-daily/; Berrisford et al. 2011). ERAInterim is a global atmospheric reanalysis from 1979, continuously updated in real time. It includes a fourdimensional variational analysis with a 12 -h analysis window assimilating surface and upper-air measurement data into the model. The spatial resolution of the reanalysis data is $1.25^{\circ}$, or approximately $80 \mathrm{~km}$ (T255 spectral) on 60 vertical levels from the surface up to $0.1 \mathrm{hPa}$. The horizontal resolution of the downloaded model data was interpolated to $0.75^{\circ}$. The time resolution of the data is $6 \mathrm{~h}$.

SOM were calculated by the freely available SOM software package (http://www.cis.hut.fi/research/somresearch). A description of the software is provided by Kohonen et al. (1996). The SOM method uses an unsupervised and objective classification procedure to 


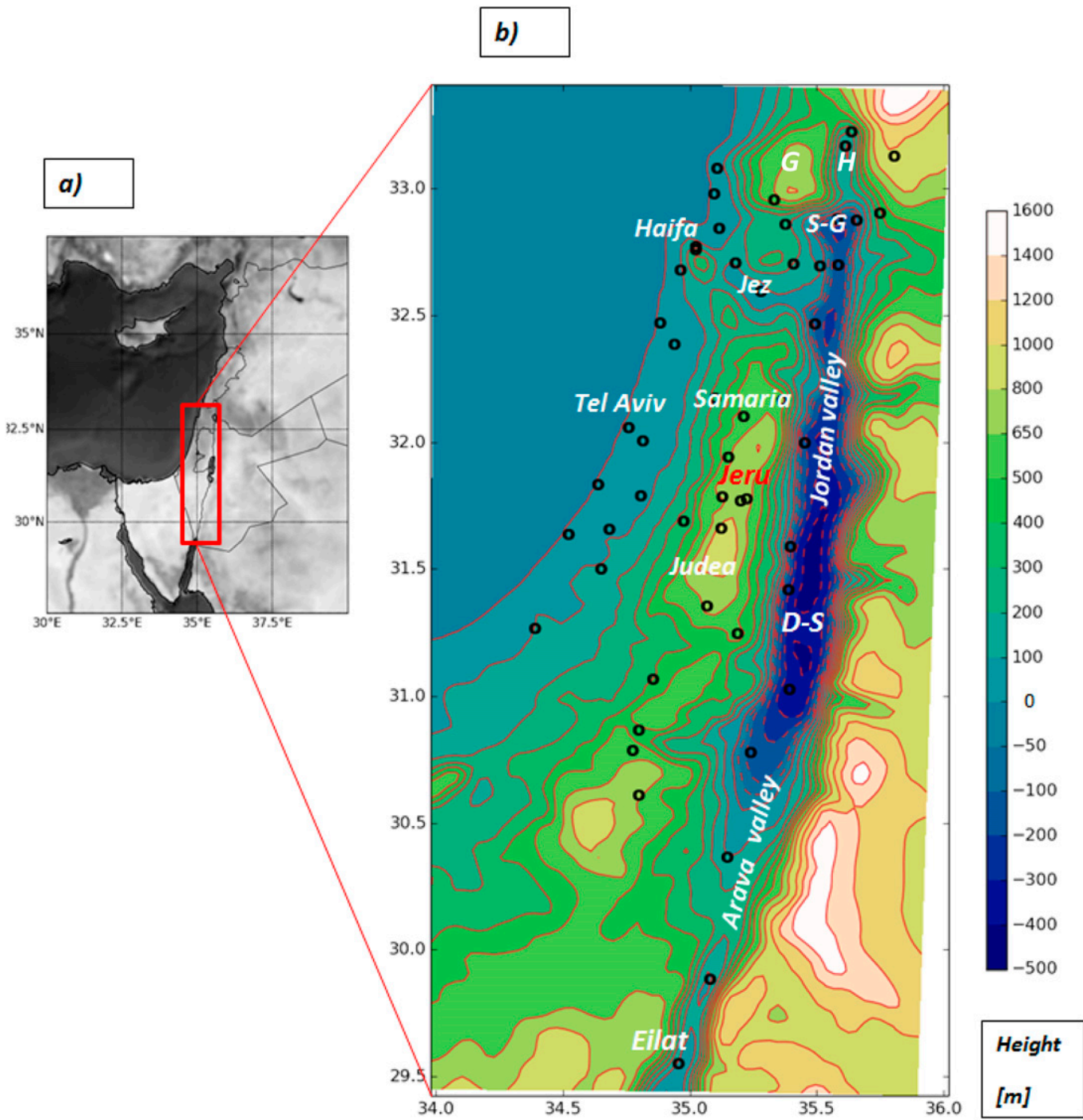

FIG. 1. (a) The eastern Mediterranean Sea region and (b) the studied area showing Jerusalem (Jeru), the Dead Sea (D-S), the Sea of Galilee (S-G), Jezreel Valley (Jez), Galilee Mountains (G), and Hula Valley (H). The locations of the 53 IMS stations are denoted by circles. The topography height relative to mean sea level $(\mathrm{m})$ is denoted by colors and contour lines.

group events into clusters. The description and application of this method to surface winds were presented by Nigro and Cassano (2014). Each cluster is identified by a common pattern designated by a node. The patterns are displayed in a two-dimensional array that is known as a map of nodes (Kohonen 2001). Unlike clustering methods, SOM does not need an initial guess of the clusters involved. The nodes present the dominant patterns ordered according to the time order presented in the dataset. Similar nodes are located next to each other, and contrasting nodes are farther apart. Very different states map to the corners and edge of the map. More nodes are clustered according to their frequency in time across the data. Each node is an approximation to the mean of its members. These facts are presented while studying the hourly surface wind patterns.

The software was applied to 10 -min wind averages from DJF 2006-12 from 53 IMS weather stations. The SOM was trained with the east-west and north-south ( $u$ and $v$ ) components of the wind data. SOM analysis was performed for all of the available data at the synoptic hours. The diurnal variability was included, and it was possible to simultaneously resolve the wind regimes at the four hours. After determining the frequency of each SOM regime at the various synoptic hours for the entire sample, a chi-square test was used to determine whether the total sample is distributed evenly among all of the synoptic-hour categories of the wind regimes. As will be 
presented in the results section, this test revealed a farfrom-uniform distribution of the synoptic-hour events at most of the wind regimes. Therefore, to characterize wind regimes at each synoptic hour it is necessary to perform a separate study for each synoptic hour. In this approach, the diurnal time scale is omitted, and it was possible to fully and independently resolve the wind regimes at each hour. Similar conclusions were obtained from the two analyses. A full comparison of the two approaches is beyond the scope of this study. Guèye et al. (2011) mention the fact that better SOM analysis is obtained when there is no mixing of time scales in the data. Each synoptic hour should have 601 data points, but the database had missing events. It was verified that at least 530 data points were found for each weather station. The "SOM PAK" software package can handle missing data points (Kohonen et al. 1996; Samad and Harp 1992). The SOM PAK routines compute the distance calculations and reference-vector modification steps using the available data components. Samad and Harp (1992) have shown examples of incomplete SOM training. When the probability of a missing datum was less than 0.6, the map entropy and RMSE were practically equal to those obtained from full-data training.

Numerous SOM examinations were performed to verify the validity of our classification. The major conclusions are described herein. The winter surface winds at all the synoptic hours were studied. SOM training is performed by an ordered examination of SOM maps. During this process, the number of the nodes increases. The process ends when a further increase of the number of nodes does not give new information. The map is a two-dimensional square array of nodes; the number of nodes in each map (the map size) is denoted by $N \times M$, indicating the number of columns $N$ and the number of rows $M$ of the map. Thus, a series of $4 \times 3,7 \times 2,5 \times 3$, $6 \times 3,7 \times 3,8 \times 3,5 \times 4$, and $6 \times 4$ maps were created to determine the best map to represent the variety of the wind patterns.

The $4 \times 3$ SOM analysis has shown low wind steadiness under five nodes. The $7 \times 2$ and $5 \times 3$ maps have shown similar wind regimes and higher steadiness (relative to the $4 \times 3$ map). A redundancy of two wind regimes was found at the $4 \times 4$ map. Larger maps have shown higher resemblance between the map nodes, along with lower frequencies. SOM nodes display patterns according to their frequency. Increasing the size of the map and keeping the size of the dataset will result in lower representativeness of the nodes.

The winter surface winds at 1200 UTC were separately studied. A series of $4 \times 2,4 \times 3,5 \times 3,6 \times 3$, and $7 \times 3$ maps was created to determine the best map to represent the variety of the wind patterns. A comparison between the SOM regimes versus the semiobjective classes was performed to find a clear division between regimes under winter lows as opposed to regimes under winter highs and Red Sea troughs $(\mathrm{RST})$. The $4 \times 3$ map was eventually selected at 1200 UTC. The same method that was used for the 1200 UTC analysis has been applied for the data at each of the remaining synoptic hours $(0000,0600$, and 1800 UTC). It was found that the $4 \times 3$ SOM map is representative at the remaining hours. Another SOM training according to data from three successive hours $( \pm 1 \mathrm{~h}$ around a synoptic hour: e.g., 1100,1200 , and 1300 UTC) [1803 $(601 \times 3)$ time events] was made to validate the classification that used data from a single synoptic hour. It was found that wind regimes that are based on 3-h data and wind regimes from a single hour of data are basically the same.

The determination of the wind regimes was followed by the calculation of the average wind field and steadiness at each node. This check ascertains that the SOM wind regime is similar to the average of its members as expected (Nigro and Cassano 2014). Since directionality is an important characteristic of the wind regime, an effort was made to choose the best SOM analysis that provides the highest degree of steadiness for most of the regimes according to the synoptic hour. SOM analysis according to data of all of the synoptic hours gave a low degree of steadiness parameter $S(S<0.5)$ at 6 of the $7 \times 2$ map nodes and 4 of the $5 \times 3$ map nodes because of the veering of the wind under a weak synoptic effect. The map with the higher degree of steadiness (i.e., $5 \times 3$ ) was selected. The SOM analysis of each synoptic hour data was performed to evaluate the steadiness of the regimes at each synoptic hour.

At each node, the average wind field and the wind steadiness were calculated (Berkovic 2016). The steadiness parameter $S$ is redefined here for clarity. The vector mean wind $M_{V}$, the mean wind speed $M_{\mathrm{sp}}$, and their ratio $S$ are defined as

$$
\begin{aligned}
M_{V} & =\left[\left(\frac{1}{N} \sum_{i=1}^{N} u_{i}\right)^{2}+\left(\frac{1}{N} \sum_{i=1}^{N} v_{i}\right)^{2}\right]^{1 / 2}, \\
M_{\mathrm{sp}} & =\frac{1}{N} \sum_{i=1}^{N}\left(u_{i}^{2}+v_{i}^{2}\right)^{1 / 2}, \text { and } \\
S & =M_{V} / M_{\mathrm{sp}}
\end{aligned}
$$

$S$ is equal to 1 when the wind flow is constant. When $S<0.5$, the wind is not steady. According to a previous study (Berkovic 2016), high $S$ values were obtained when the standard deviation of the wind direction was relatively small $\left(<60^{\circ}\right)$.

To study the relation between the synoptic parameters and the local wind regimes, the averages of the 
synoptic variables, derived from the ERA-Interim data, were calculated at each node. Each average is an average over all the events classified for a certain wind regime. The effect of the synoptic pressure on the diurnal flow is studied by calculating the averages of the geopotential height ("ERA-Igp") surface anomalies (Nigro and Cassano 2014) for every wind pattern. The anomalies facilitate the comparison between the wind regimes at different hours since the effect of the average geopotential height is removed. It is the pressure gradient that is responsible for the wind field and not the absolute value of the geopotential height. The average ERA-Igp was calculated for a domain of $15 \times 15$ grid points around Israel between latitudes $27^{\circ}$ and $38.25^{\circ} \mathrm{N}$ and between longitudes $29.25^{\circ}$ and $40.5^{\circ} \mathrm{E}$. The anomaly was calculated by removing the area average at each time step. A very similar area was chosen by Alpert et al. (2004) to define the semiobjective synoptic classes over the EM. Therefore, it is easy to relate to previous familiar semiobjective synoptic classes. The typical pressure gradients according to the semiobjective classification were presented in Berkovic (2016). It was separately found that separate $4 \times 3 \mathrm{SOM}$ maps from analysis of $925-\mathrm{hPa}$ ERA-Igp anomalies at each synoptic hour are highly related to the observed wind regimes described in this work (not shown). The ERA-Interim temperature and humidity averages at each wind regime are presented over a smaller domain between $30.75^{\circ}$ and $37.5^{\circ} \mathrm{E}$ and between $27^{\circ}$ and $37^{\circ} \mathrm{N}$ to inspect the temperature and specific humidity over Israel. Israel is covered by only six grid points between longitudes $34.5^{\circ}$ and $35.25^{\circ} \mathrm{E}$ and between latitudes $33^{\circ}$ and $30^{\circ} \mathrm{N}$

The connection between SOM wind regimes and the semiobjective classification was found according to the separate 1200 UTC SOM $4 \times 3$ classification against the semiobjective classification defined according to National Centers for Environmental PredictionNational Center for Atmospheric Research reanalysis data at 1200 UTC. A full description of this classification is given in Alpert et al. (2004) and Osetinsky (2006). The semiobjective classification data were kindly provided by Alpert et al.

\section{Synoptic classes and groups}

The synoptic classes for the EM were mentioned in previous works (e.g., Alpert et al. 2004; Osetinsky 2006; Berkovic 2016). The following description of the main groups was given in Berkovic (2016) and is briefly repeated here for the benefit of the reader. The winter groups and classes are summarized in Table 1.
TABLE 1. The winter synoptic groups and classes.

\begin{tabular}{lll}
\hline \multicolumn{1}{c}{ Group } & \multicolumn{1}{c}{ Class } & Acronym \\
\hline Red Sea troughs & Red sea trough to the east & $\mathrm{RST}_{\mathrm{E}}$ \\
& Red sea trough center & $\mathrm{RST}_{\mathrm{C}}$ \\
Highs & High to the west & $\mathrm{H}_{\mathrm{W}}$ \\
& High center & $\mathrm{H}_{\mathrm{C}}$ \\
& High to the north & $\mathrm{H}_{\mathrm{N}}$ \\
& High to the east & $\mathrm{H}_{\mathrm{E}}$ \\
Lows & Deep low to the east & $\mathrm{L}_{\mathrm{E}}-\mathrm{D}$ \\
& Deep Cyprus low to the north & $\mathrm{CL}_{\mathrm{N}}-\mathrm{D}$ \\
& Shallow Cyprus low to the north & $\mathrm{CL}_{\mathrm{N}}-\mathrm{S}$ \\
& Cold low to the west & $\mathrm{L}_{\mathrm{W}}$ \\
& Shallow low to the east & $\mathrm{L}_{\mathrm{E}}-\mathrm{S}$ \\
Undefined & & - \\
\hline
\end{tabular}

There are four relevant groups:

1) "Winter lows" includes two subgroups that together form the dominant synoptic group during winter: the regular winter lows [L; i.e., low to the west $\left(\mathrm{L}_{\mathrm{W}}\right)$, deep low to the east $\left(\mathrm{L}_{\mathrm{E}}-\mathrm{D}\right)$, and shallow low to the east $\left.\left(\mathrm{L}_{\mathrm{E}}-\mathrm{S}\right)\right]$ and Cyprus lows to the north (CL; i.e., $\mathrm{CL}_{\mathrm{N}^{-}} \mathrm{D}$ and $\mathrm{CL}_{\mathrm{N}}-\mathrm{S}$ ). Group $\mathrm{CL}$ is responsible for the largest amount of rain in the EM. Each Cyprus low contributes rainfall during 2-3 consecutive days.

2) Highs $(\mathrm{H})$ come in two types. The first is the "Siberian highs" [winter highs to the north $\left(\mathrm{H}_{\mathrm{N}}\right)$ and to the east $\left.\left(\mathrm{H}_{\mathrm{E}}\right)\right]$ that occur mainly during the cool season. Siberian highs are highs of a northern origin-from Europe (e.g., Romania, Turkey, and Caucasia) or Siberia (the winter Asiatic monsoon) itself. The extension of the Siberian high is rare, occurring once every few years. Winter highs bring fair weather, inducing cold, dry winds over Israel. The second type is the "subtropical high" [the high to the west of Israel $\left(\mathrm{H}_{\mathrm{W}}\right)$ ], which may occur throughout the year. It is an extension of the Azorean high, which is prevalent over North Africa.

3) The RST, a trough over the Red Sea and its surroundings, is an extension of a low over the Sudan that may occur during the transition months or during winter. It is often accompanied by $\mathrm{H}_{\mathrm{N}}$ or $\mathrm{H}_{\mathrm{E}}$.

4) Undefined days were mentioned in the subjective classification (Levy et al. 2010; Dayan and Levy 2002). They present weak pressure gradients under transition between two defined classes.

In some cases, a surface pressure gradient map may be classified under two classes (Dayan et al. 2012; Osetinsky 2006), and ambiguity is created. In the case of wind regimes, the exact classification is not necessary since various classes may lead to similar wind regimes (Berkovic 2016). 


\section{Results}

\section{a. United $5 \times 3$ SOM frequencies}

A SOM analysis of all the events from all of the synoptic hours gave a $5 \times 3$ map, representing the dominant wind regimes at these hours. The number of events at each synoptic hour under each $5 \times 3$ SOM node is tabulated in Fig. 2. Each row represents the number of events found at each synoptic hour for that node. The green column presents the sum of these events. It is seen that the frequencies are not necessarily distributed uniformly among the synoptic hours. The rightmost column presents the expected number of events under the assumption of a homogeneous distribution of events at all of the synoptic hours. Nodes 2 and 15 have a nearly uniform distribution of frequencies, whereas most of the other nodes have major contribution from 1200 UTC events (regimes 13 and 14), 0000 and 0600 UTC events (regimes 3-5 and 10), or 1200 and 1800 UTC events (regimes 7 and 13). The highest frequency is found at nodes 15 and 3: $274(11 \%)$ and $233(10 \%)$, respectively. The lowest frequency is found at node 11 (114; 5\%). Nearly uniform distribution results from a strong synoptic effect on the diurnal flow. Nonuniform distribution shows that the orography and the diurnal heating have strong effects on the wind regimes, leading to different nodes of nighttime or daytime events. The result of a chi-square test was 0 , which means a rejection of the null hypothesis that the distribution of the synoptic hour events is independent of the wind regimes. Therefore, to examine wind regimes at each hour a separate SOM analysis is required. The differences between 0000 UTC wind regimes and 1200 UTC wind regimes at each of the 15 categories cannot be calculated because of the vast differences between their frequencies at most of the categories.

\section{b. Winter wind regimes at 0000 and 1200 UTC}

A separate SOM analysis at each of the synoptic hours during DJF (winter) was performed. Wind regimes at 1200 and at 0000 UTC according to $4 \times 3$ SOM will be presented and discussed. An examination of the wind regimes (according to the united $5 \times 3$ and a separate $4 \times 3 \mathrm{SOM})$ at each synoptic hour revealed similarity between the 0000 and 0600 UTC regimes and between the 1200 and 1800 UTC regimes. Therefore, these results depict the full range of wind regimes that occur during winter at each of the synoptic hours. In all figures, the vectors display the average surface wind at each SOM node. The $S$ is denoted by circles according to size and color. The nodes are numbered sequentially from 1 to 12. The frequency (average number of events for all 53 stations) is displayed at the top of each

\begin{tabular}{|c|c|c|c|c|c|c|}
\hline & $0 Z$ & $6 Z$ & $12 Z$ & $18 Z$ & tot & $\exp$ \\
\hline 1 & 23 & 30 & 69 & 21 & 143 & 35.75 \\
\hline 2 & 40 & 58 & 39 & 22 & 159 & 39.75 \\
\hline 3 & 83 & 93 & 5 & 52 & 233 & 58.25 \\
\hline 4 & 65 & 50 & 3 & 27 & 145 & 36.25 \\
\hline 5 & 40 & 58 & 15 & 22 & 135 & 33.75 \\
\hline 6 & 26 & 17 & 55 & 31 & 129 & 32.25 \\
\hline 7 & 23 & 17 & 46 & 45 & 131 & 32.75 \\
\hline 8 & 55 & 34 & 15 & 75 & 179 & 44.75 \\
\hline 9 & 68 & 56 & 0 & 57 & 181 & 45.25 \\
\hline 10 & 51 & 59 & 9 & 28 & 147 & 36.75 \\
\hline 1 & 16 & 14 & 55 & 29 & 114 & 28.5 \\
\hline 12 & 13 & 8 & 77 & 31 & 129 & 32.2 \\
\hline 13 & 9 & 7 & 96 & 58 & 170 & 42 \\
\hline 14 & 23 & 18 & 50 & 44 & 135 & 33.75 \\
\hline 5 & 66 & 82 & 67 & 59 & 274 & 68 \\
\hline
\end{tabular}

FIG. 2. Number of events according to $5 \times 3$ SOM regimes at each synoptic hour (red). The total (tot) number of events is presented in the fifth (green) column. The number of events expected (exp) according to the assumption of a homogeneous distribution is given in the rightmost column.

subfigure. When presenting the average surface wind, around $1 \%$ is lost because of weak winds (speed $<$ $0.5 \mathrm{~m} \mathrm{~s}^{-1}$ ). The weak-winds events were included in the SOM analysis, but they were omitted from the windaverages calculation in order to obtain the average wind direction under weak wind regimes. It is not possible to get an indicative wind direction for wind speeds of less than $0.5 \mathrm{~m} \mathrm{~s}^{-1}$.

From inspections of the SOM maps at all of the synoptic hours, three dominant wind patterns are revealed:

1) western and southern wind, which includes the strong $\left(5-10 \mathrm{~m} \mathrm{~s}^{-1}\right)$ western flow over Israel (category A),

2) eastern and northern flow, which includes the strong $\left(5-10 \mathrm{~m} \mathrm{~s}^{-1}\right)$ eastern flow to the north of Israel and at the top of the ridges in the Judea and Samaria Mountains (category B), and

3) relatively low speed $\left(<4 \mathrm{~m} \mathrm{~s}^{-1}\right)$ and directionality according to the diurnal heating and local topography or no directionality (category C).

These wind regimes are known and have been respectively subjectively categorized (Saaroni et al. 1998; Levy et al. 2008; Goldreich 2003; Ziv and Yair 1994) 
according to the following synoptic groups (Alpert et al. 2004; Dayan et al. 2012):

1) winter lows and highs from the west,

2) winter highs and Red Sea trough, and

3) shallow classes, such as high over Israel, shallow low to the west, shallow high to the west, and shallow RST.

The wind regimes at 0000 and 1200 UTC will be hereinafter described according to the three dominant wind categories.

\section{1) Surface Wind Regimes at 1200 UTC}

The wind patterns at 1200 UTC are displayed in Fig. 3. For category A (western wind), the strong (4-10 $\mathrm{m} \mathrm{s}^{-1}$ ) western wind regimes (nodes 4, 8, and 12; Fig. 3) relate to the location and pressure gradient of the winter lows (Ziv and Yair 1994). Along the Jordan and Arava Valleys, the steadiness is lower (nodes 8 and 12; Fig. 3).At node 4 (Fig. 3), the steadiness along the valley increases.

For category B (eastern wind), the strong easterly wind $\left(\sim 10 \mathrm{~m} \mathrm{~s}^{-1}\right)$ in northern Israel and at the top of Judea and Samaria Mountains was obtained at nodes 1 and 5 (Fig. 3). These regimes are known and were previously described by Saaroni et al. $(1996,1998)$ and Goldreich (2003). They occur under Lw, winter highs $\left(\mathrm{H}_{\mathrm{N}}\right.$ and $\mathrm{H}_{\mathrm{E}}$ ), and RSTs. At nodes 5 and 9 (Fig. 3) along the central coastal plain, the northwest wind indicates the opposing effect of the local sea breeze. Along the Dead Sea and the Arava Valley, northeast upslope wind (along the western slope of the Jordan Valley) is obtained according to the direction of the synoptic pressure gradients under RST and winter highs $\left(\mathrm{H}_{\mathrm{N}}, \mathrm{H}_{\mathrm{E}}\right.$, and high center $\mathrm{H}_{\mathrm{C}}$ ) (nodes 1, 5, 9, 6, and 10; Fig. 3).

Category $\mathrm{C}$ (weak wind) is characterized by weak average winds (speed $\leq 4 \mathrm{~m} \mathrm{~s}^{-1}$ ) and low steadiness $(<0.8)$. At these regimes, the local orography affects the wind field. Western wind component is exhibited along the coast (sea breeze and upslope winds along the western slopes of the Judea and Samaria Mountains). An easterly wind component is found (upslope winds) over the eastern slopes of the Judea and Samaria Mountains (nodes 2, 3, and 10; Fig. 3).

\section{2) Surface WIND REgimes AT 0000 UTC}

The average wind regimes at 0000 UTC are displayed in Fig. 4. Similar to previous 1200 UTC wind regimes (Fig. 3), the effect of winter lows is found at nodes 3, 4, 8, and 12 and the effect of the winter highs and RST is evident at nodes 1, 2, 5, and 9. For group A (western wind), along the central coast under winter lows (nodes 8 and 12; Fig. 4) a south-southeast wind is prevalent, whereas at 1200 UTC (nodes 8 and 12; Fig. 3) it is southwest-west. These differences may be explained by the effect of the local east-southeast flow along the coast and the western slopes during the night. The wind patterns at node 4 at 0000 and 1200 UTC (Figs. 3 and 4) are similar as a result of deeper pressure gradients. According to the semiobjective classification (Berkovic 2016) over the central coastal plain at 0000 UTC, southsouthwest winds are prevalent under $\mathrm{CL}_{\mathrm{N}}-\mathrm{D}$ and $\mathrm{L}_{\mathrm{E}}-\mathrm{D}$. Along the Dead Sea and the northern part of the Arava Valley, south wind is prevalent in accordance with the local topography and the effect of the synoptic southwest wind. The wind around the Dead Sea was measured by Bitan (1977). During winter, an enhanced effect of winter lows on the local winds (Dead Sea breeze and the Mediterranean breeze) and lower directionality of winds at nighttime versus daytime were found.

For group B (eastern and northern wind), the wind regimes at nodes 1, 2, and 5 (Figs. 3 and 4) at 0000 and 1200 UTC are similar as a result of strong synoptic pressure gradients (winter highs and RST). During the night hours, the synoptic wind direction (according to 1000-hPa ERA-Interim data) is nearly parallel to the local (breeze and mountain flow) wind direction along the coast and the northern part of Israel.

For group $\mathrm{C}$ (weak wind), under weak pressure gradients (nodes 3, 6, 7, 10, and 11; Fig. 4), the wind steadiness at 0000 UTC is lower than at 1200 UTC. This fact can be explained by the increased thermal stability during the night hours, enhancing the effect of the local topography and temperature gradients. Along the coast and the western slope of the Judea and Samaria Mountains, according to the land breeze and the downslope wind, mostly an east-southeast wind is prevalent. Low similarity between the wind patterns of 0000 and 1200 UTC was obtained as a result of the differences between the directionality of the local winds during daytime and nighttime.

The wind regimes at 0000 and 1200 UTC were determined independently for each hour by different SOM analyses. Since different SOM classifiers were used for each hour (Jolly et al. 2016), these classes are not quantitatively comparable. Therefore, only similarity between composites can be seen (Figs. 3 and 4).

The average ERA-Igp anomalies according to 1200 and 0000 UTC wind regimes were calculated at the various pressure levels: 500, 850, 925, and $1000 \mathrm{hPa}$. The minimum difference between 0000 and 1200 UTC average ERA-Igp anomalies was found at $925 \mathrm{hPa}$. These averages are displayed in Figs. 5a and 6. The differences between the 925-hPa average ERA-Igp anomalies at 0000 and 1200 UTC are smaller than the RMSE of the ERA-Igp anomalies at each hour (from -100 to $100 \mathrm{~m}^{2} \mathrm{~s}^{-2}$; not shown). This fact enables 
a)

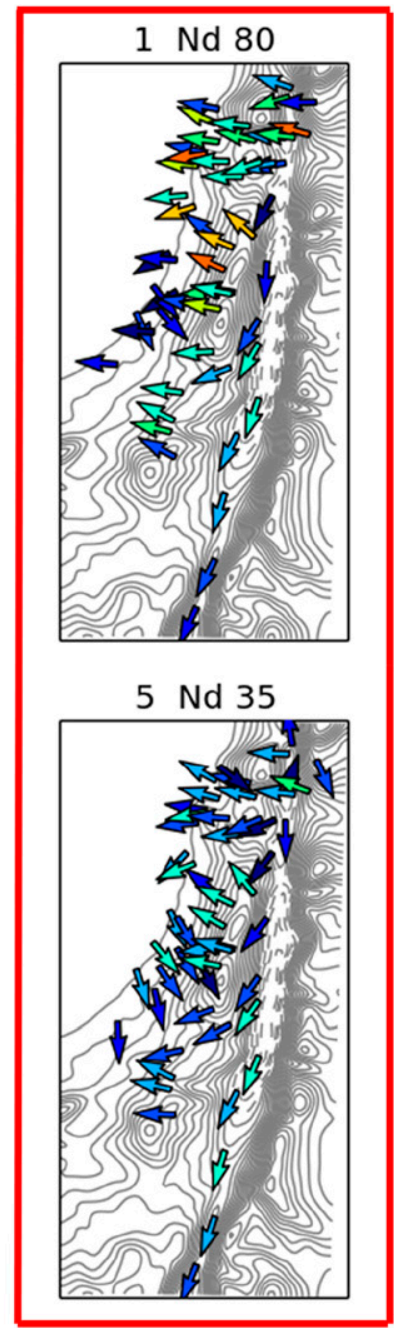

$9 \mathrm{Nd} 39$

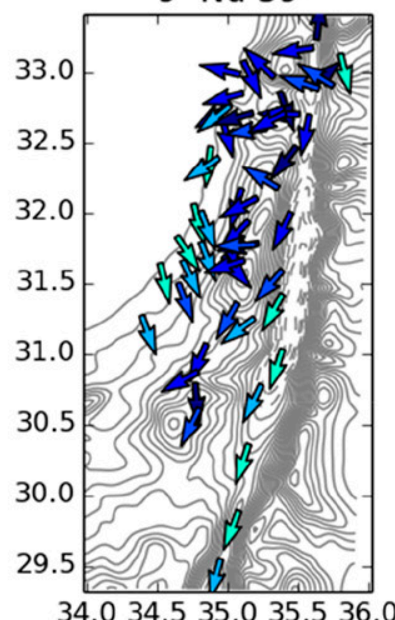

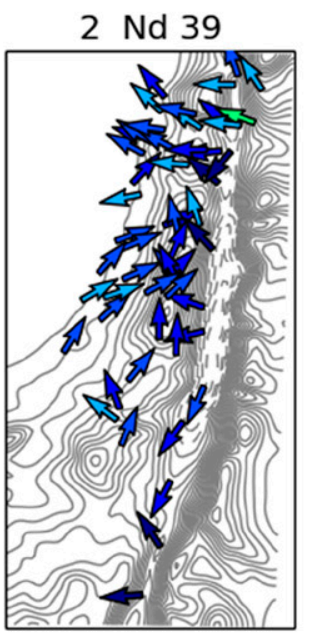

$6 \mathrm{Nd} 47$

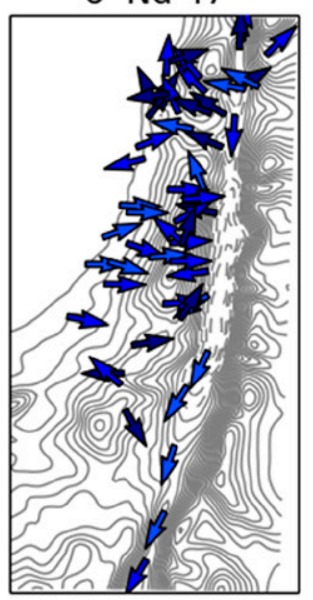

$10 \mathrm{Nd} 38$

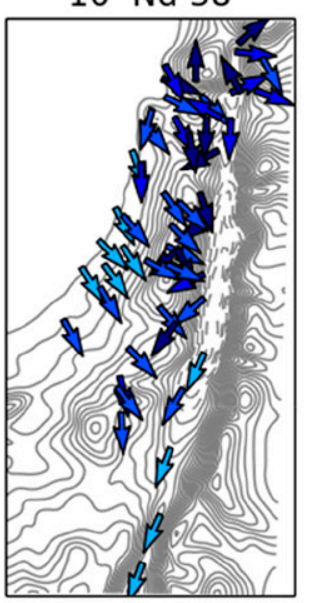

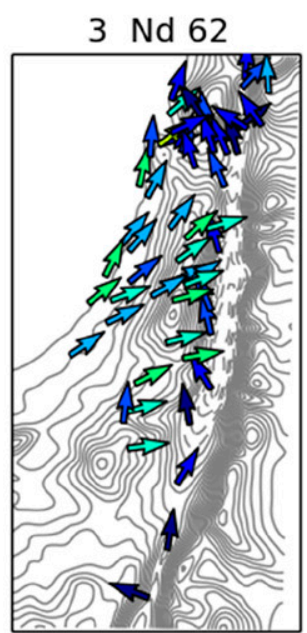

$7 \mathrm{Nd} 51$

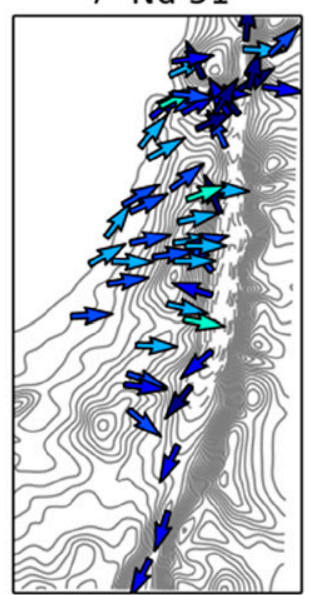

$11 \mathrm{Nd} 48$

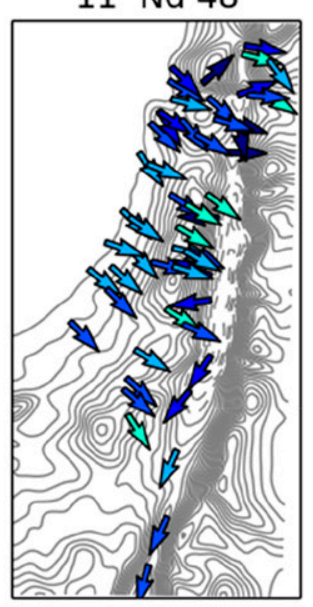

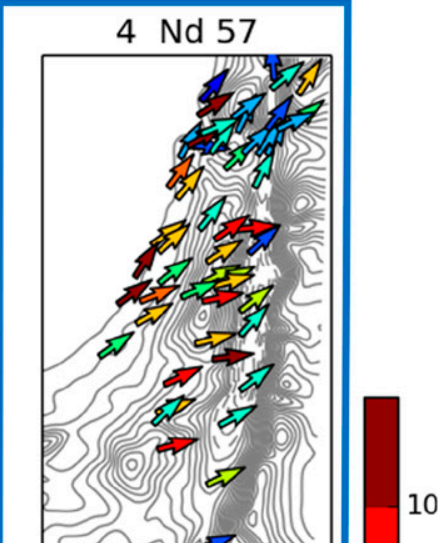

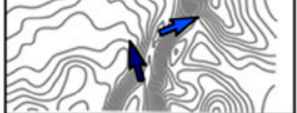

$8 \mathrm{Nd} 40$
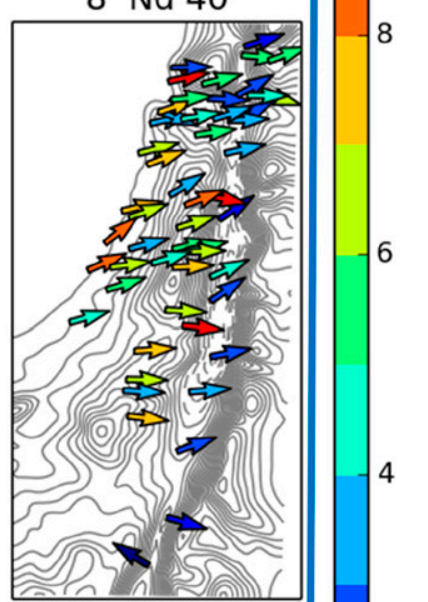

$12 \mathrm{Nd} 41$

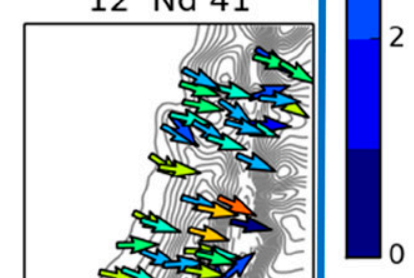

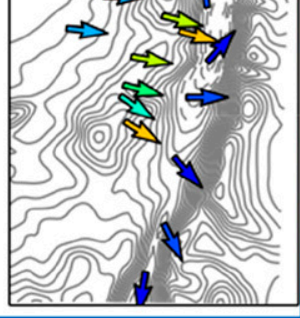

FIG. 3. The 1200 UTC DJF (a) average surface wind $\left(\mathrm{m} \mathrm{s}^{-1}\right.$ ) patterns and (b) $S$. These values were calculated according to $4 \times 3$ SOM classification. The node number and the average (over the 53 stations) number of events Nd are shown at the top of each subfigure. The red outline in (a) designates strong eastern wind regimes. The blue outline in (a) designates strong western wind regimes. 
b)

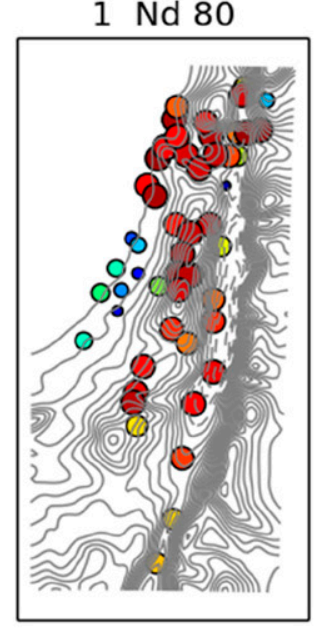

$5 \mathrm{Nd} 35$

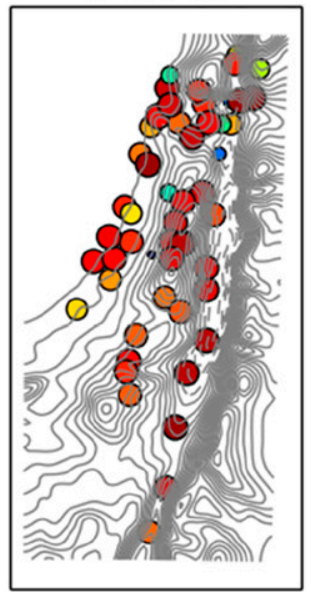

9 Nd 39

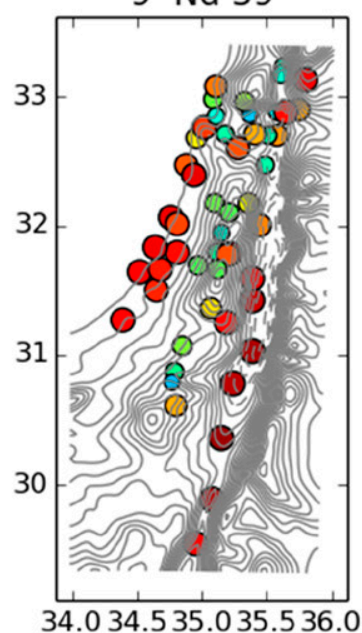

$2 \mathrm{Nd} 39$

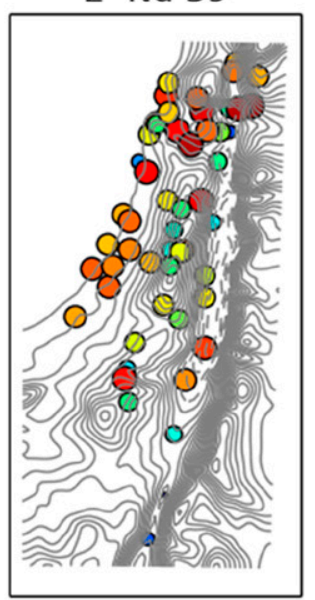

$6 \mathrm{Nd} 47$

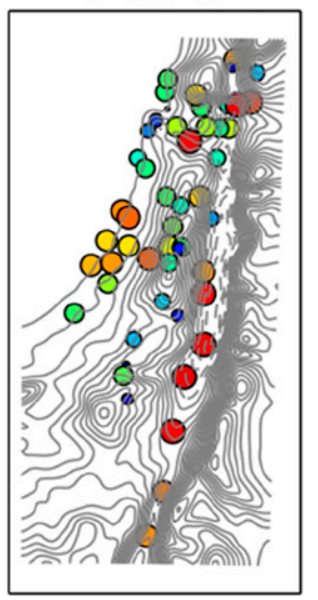

$10 \mathrm{Nd} 38$

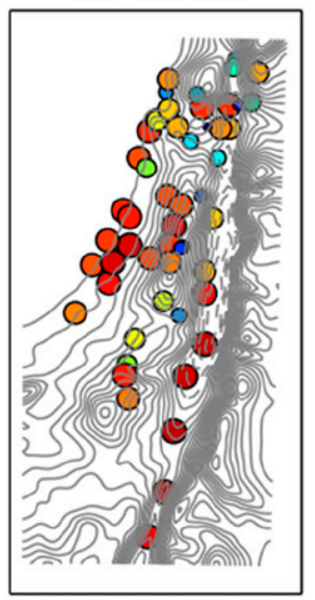

$3 \mathrm{Nd} 62$

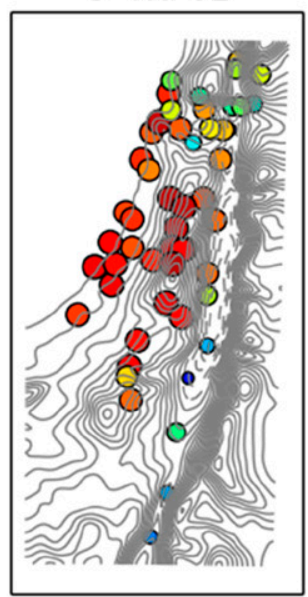

$7 \mathrm{Nd} 51$

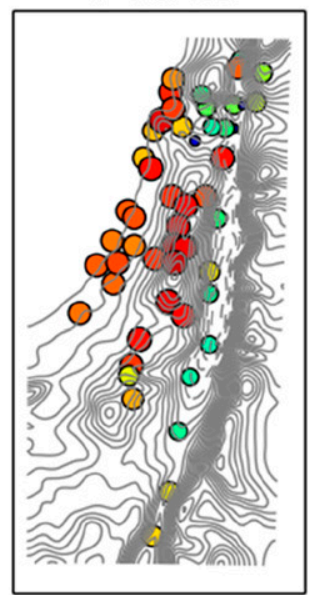

$11 \mathrm{Nd} 48$

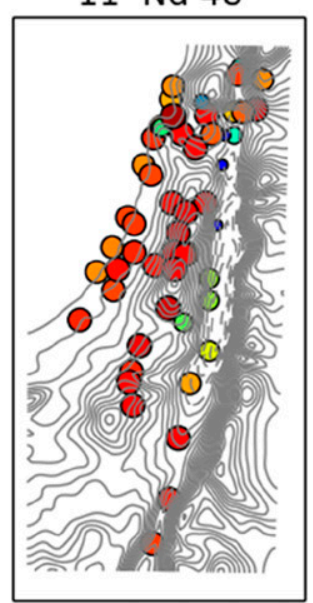

4 Nd 57

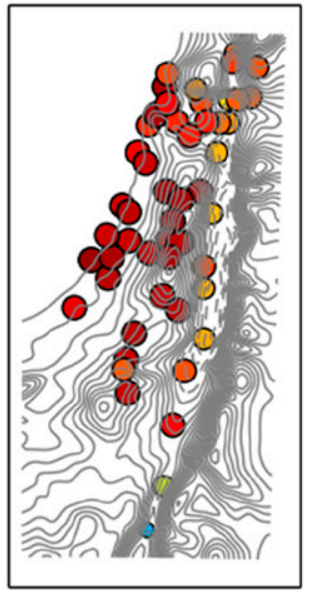

$8 \mathrm{Nd} 40$

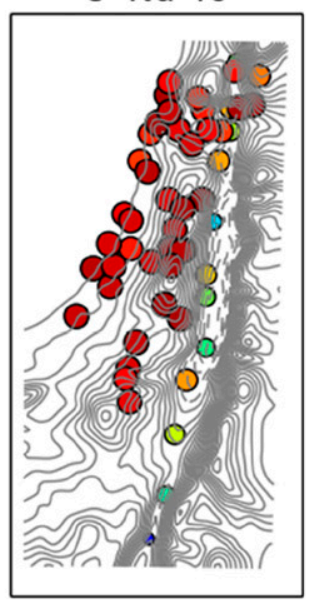

$12 \mathrm{Nd} 41$

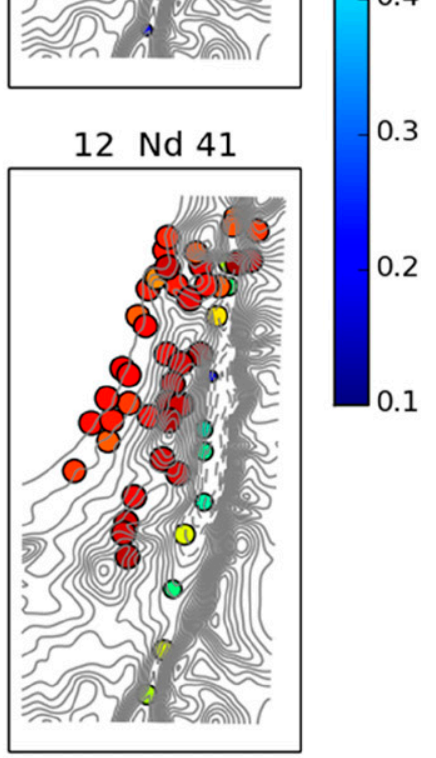

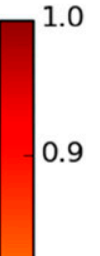

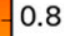

0.7

0.6

0.5

0.4

FIG. 3. (Continued) 
a)

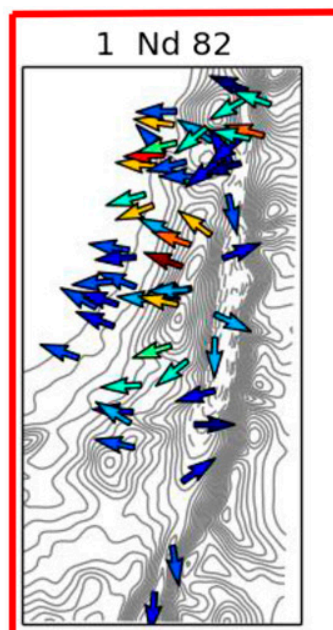

$5 \mathrm{Nd} 46$

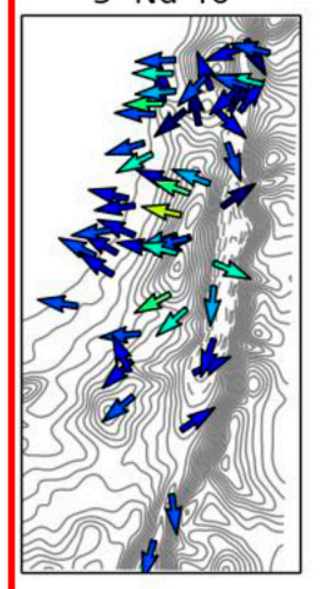

$9 \mathrm{Nd} 50$

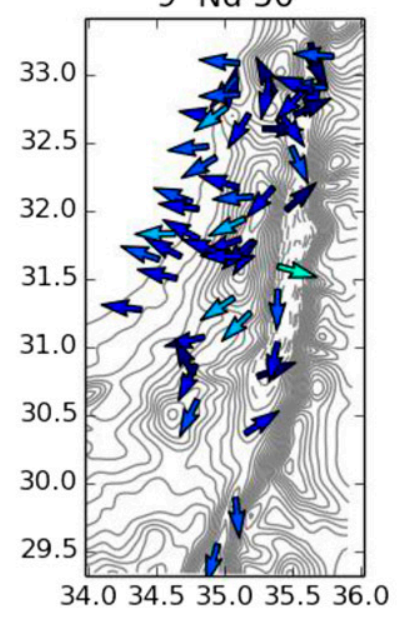

$2 \mathrm{Nd} 25$

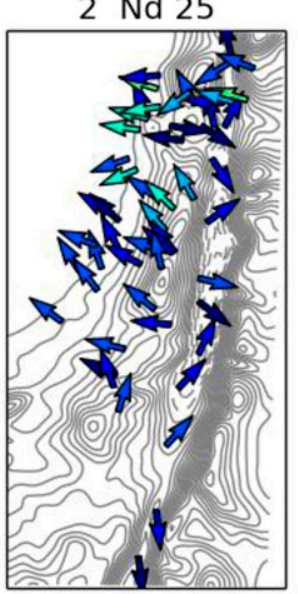

$6 \mathrm{Nd} 37$

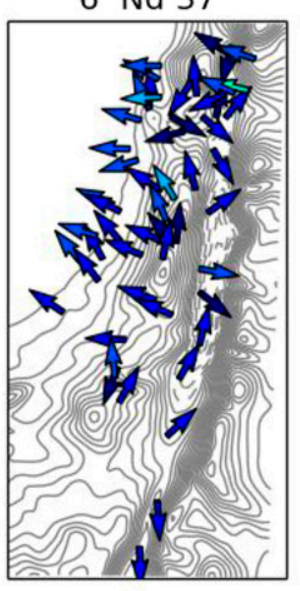

$10 \mathrm{Nd} 53$

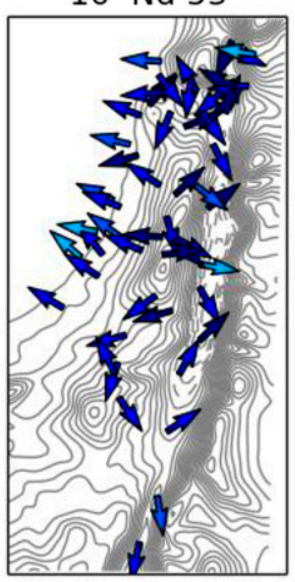

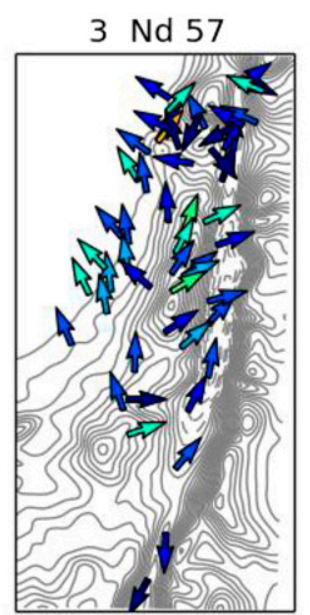

$7 \mathrm{Nd} 31$

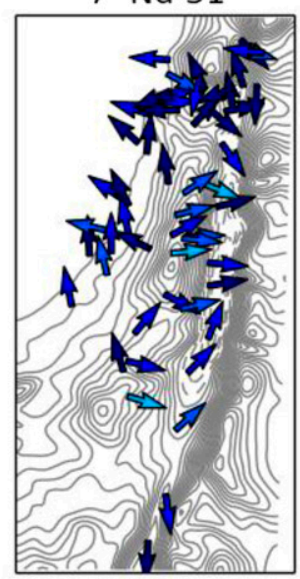

$11 \mathrm{Nd} 61$

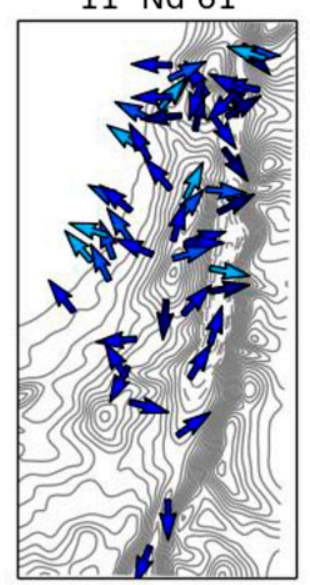

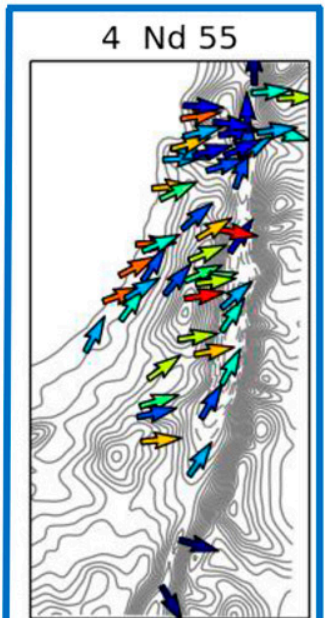

$8 \mathrm{Nd} 28$
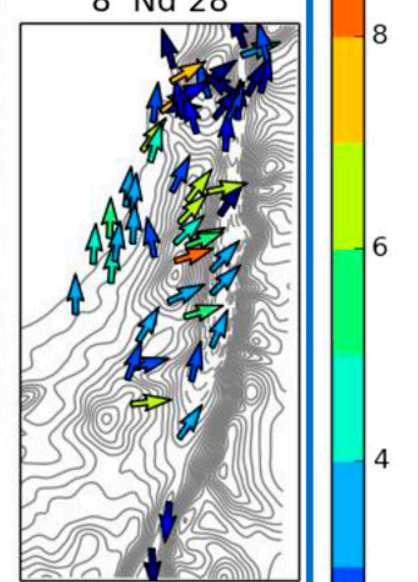

$12 \mathrm{Nd} 27$

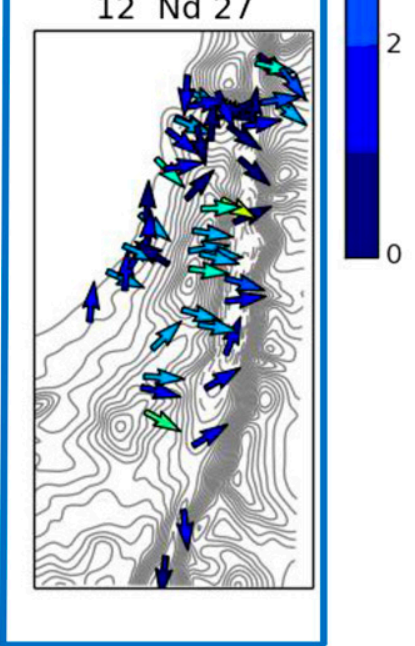

FIG. 4. As in Fig. 3, but for 0000 UTC. 
b)

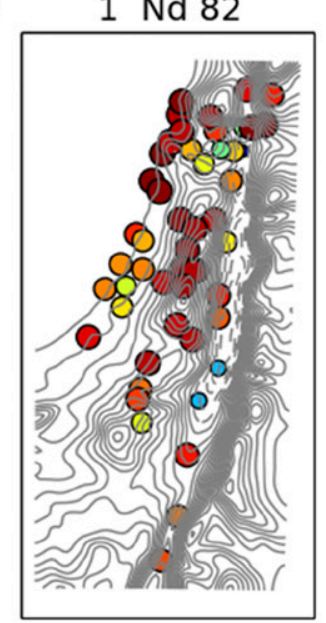

$5 \mathrm{Nd} 46$

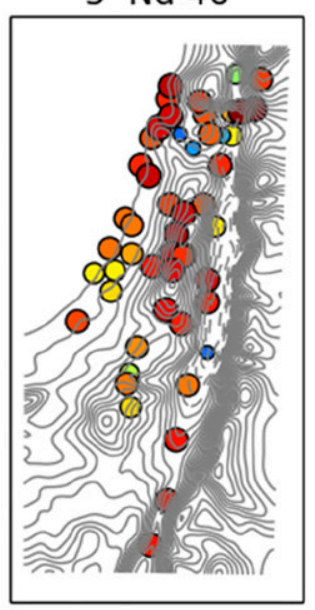

9 Nd 50

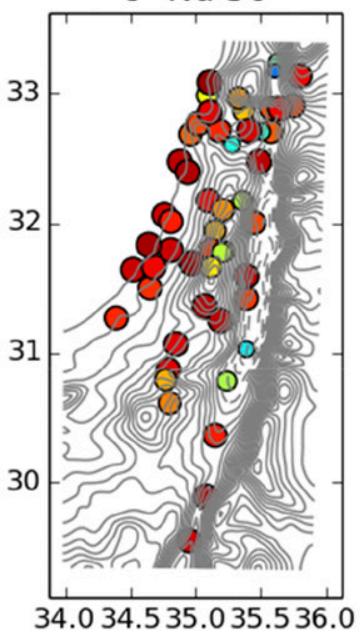

$2 \mathrm{Nd} 25$

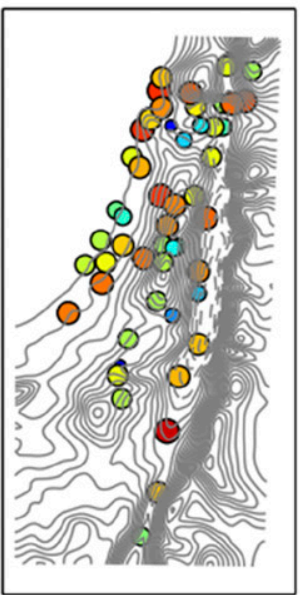

$6 \mathrm{Nd} 37$

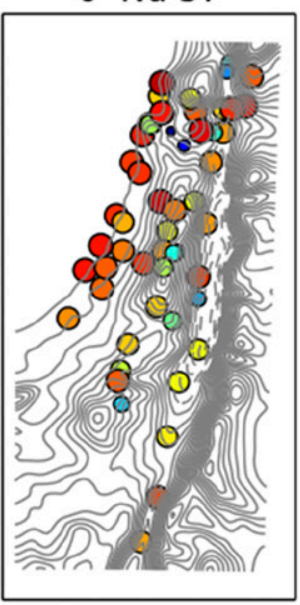

$10 \mathrm{Nd} 53$

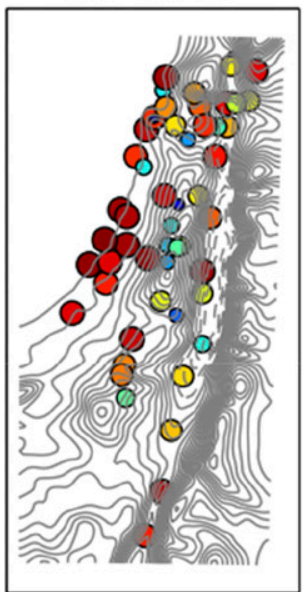

$3 \mathrm{Nd} 57$

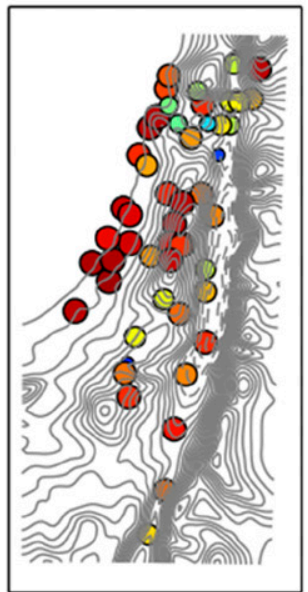

$7 \mathrm{Nd} 31$

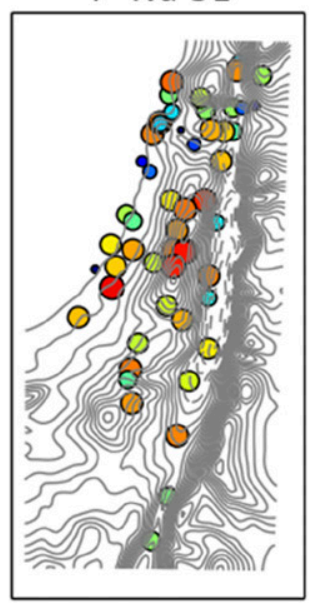

$11 \mathrm{Nd} 61$

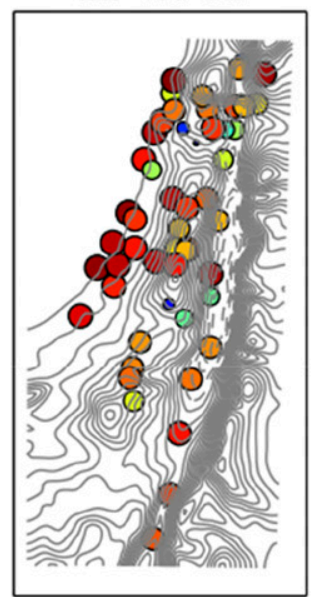

$4 \mathrm{Nd} 55$

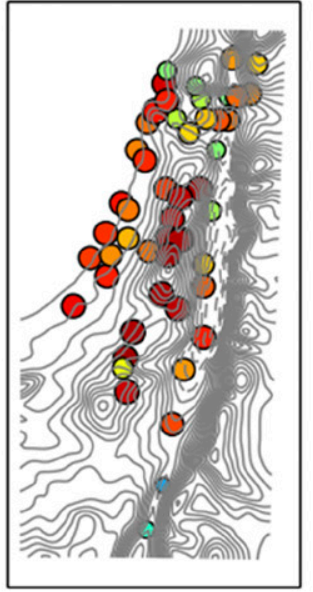

0.8

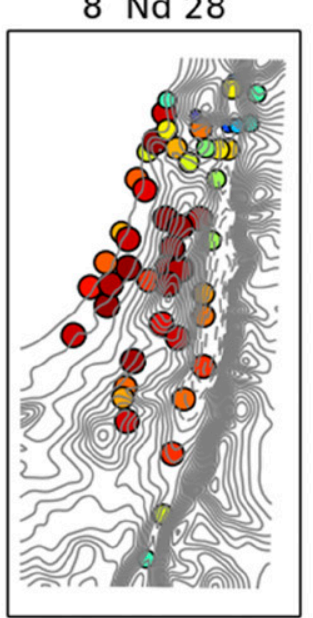

0.7

0.6

0.5

0.4
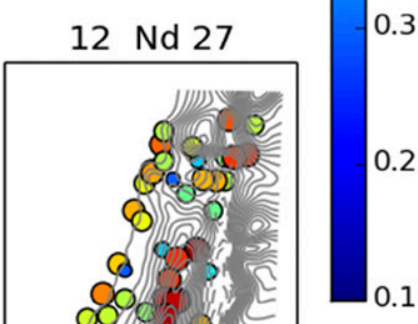

0.1

FIG. 4. (Continued) 
a)
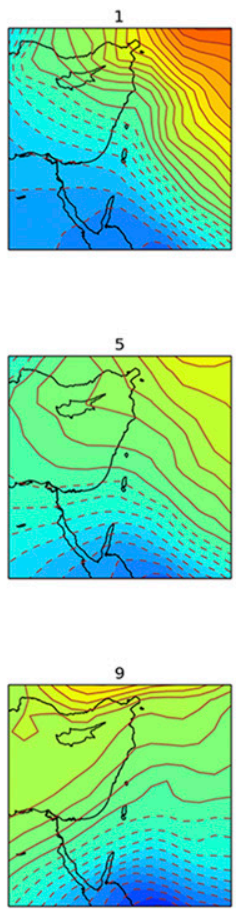

1

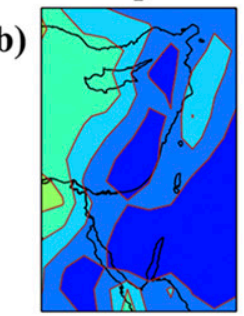

5

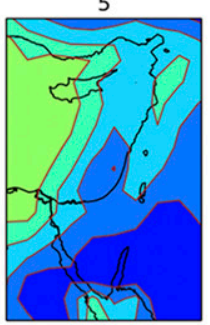

9

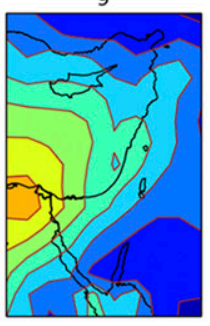

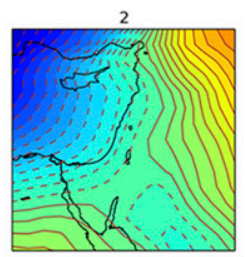
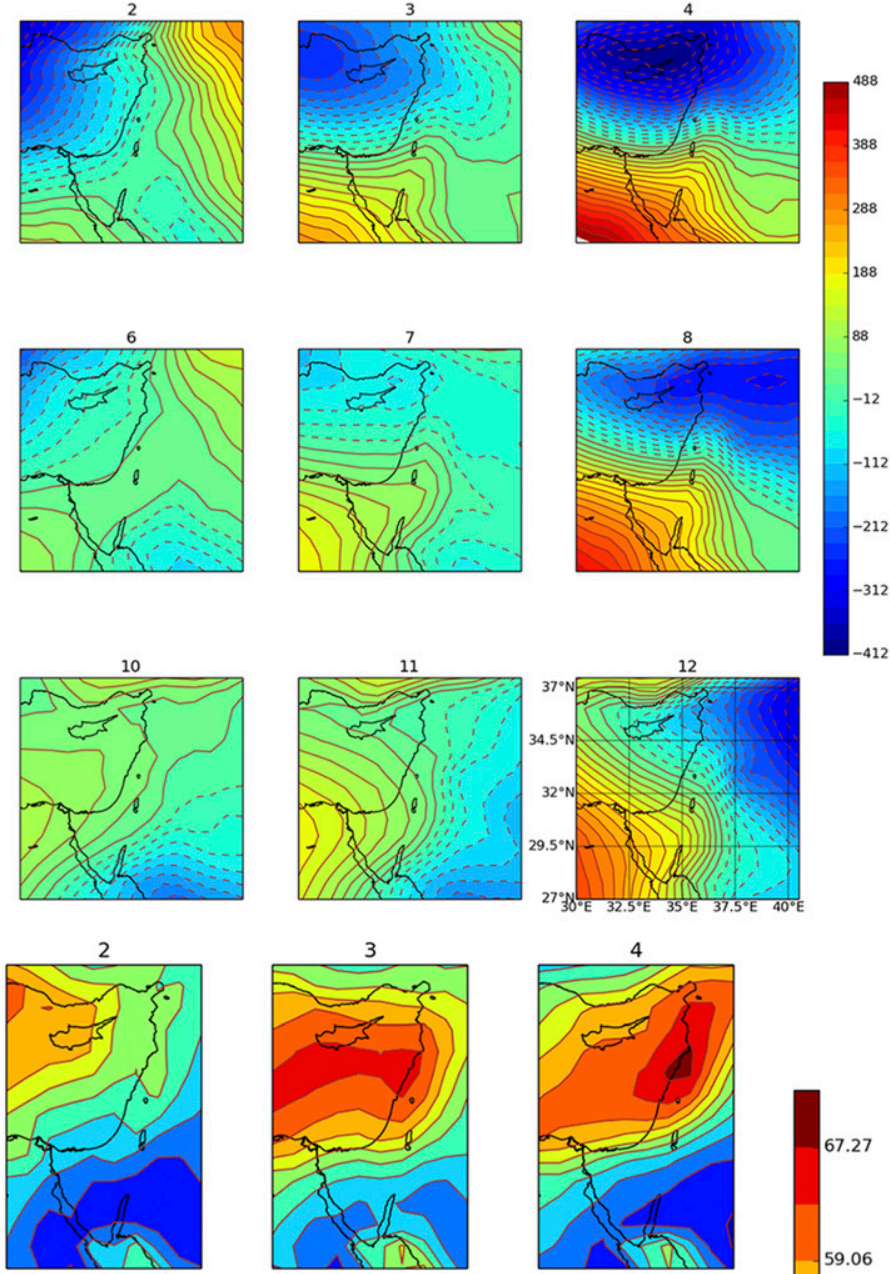
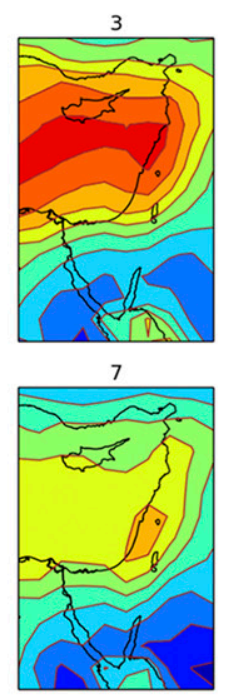

11

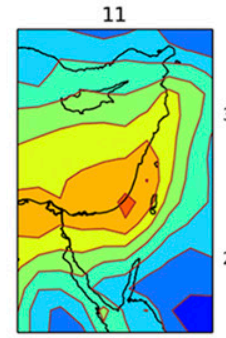

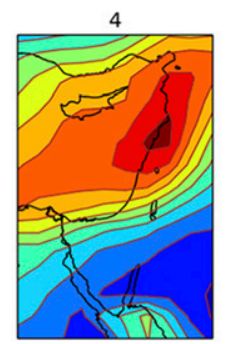

8

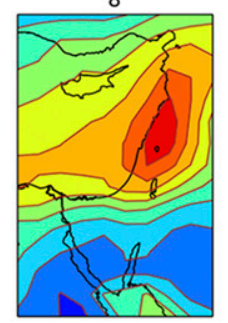

12

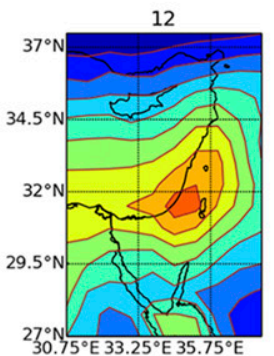

6

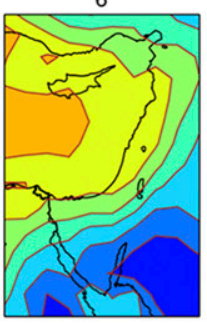

10
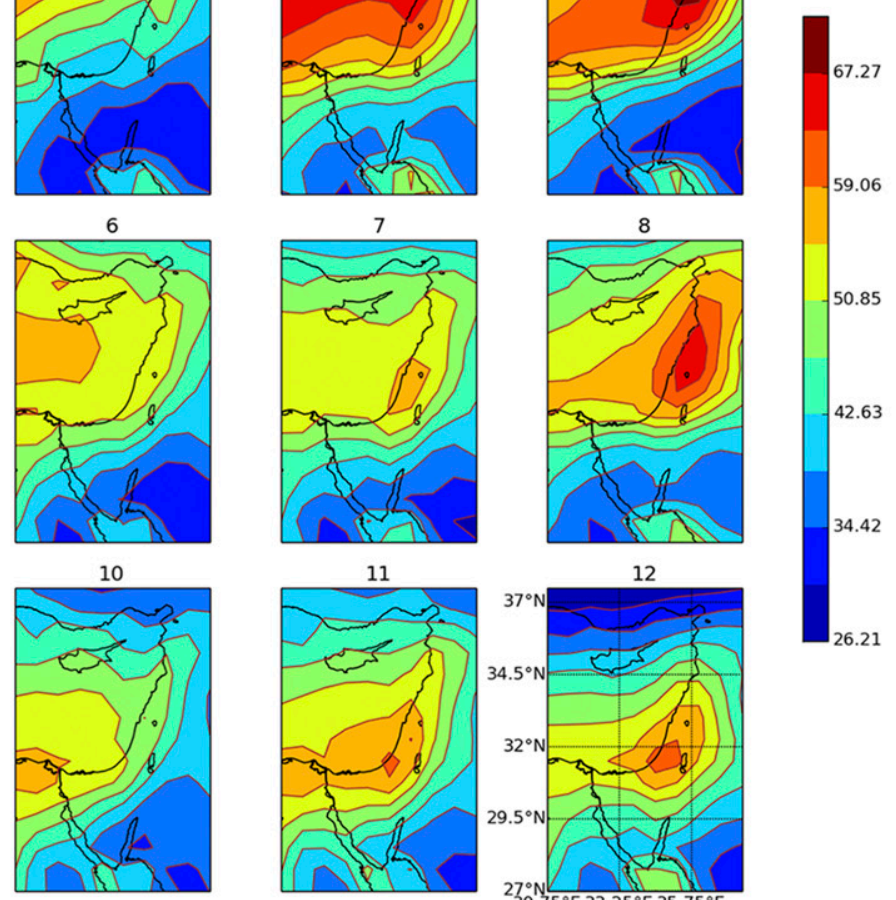

50.85 42.63

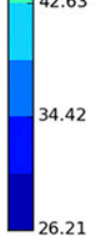

FIG. 5. The 1200 UTC DJF ERA-Interim averages according to $4 \times 3$ SOM wind regimes (displayed in Fig. 3). The node number is shown at the top of each subfigure. (a) Average geopotential height anomalies over the EM $\left(\mathrm{m}^{2} \mathrm{~s}^{-2}\right)$ at $925 \mathrm{hPa}$. The gap between neighboring isobars is $25 \mathrm{hPa}$. The RMSE over Israel is mostly $25-75 \mathrm{~m}^{2} \mathrm{~s}^{-2}$, with higher values of $50-100 \mathrm{~m}^{2} \mathrm{~s}^{-2}$ under deep lows (nodes 3, 4, 8, and 12). (b) Average specific humidity $\left(\mathrm{dg} \mathrm{kg}^{-1}\right)$ at $925 \mathrm{hPa}$ over Israel. (c) Average temperature $\left({ }^{\circ} \mathrm{C}\right)$ at $1000 \mathrm{hPa}$ over Israel. (d) Average synoptic wind $\left(\mathrm{m} \mathrm{s}^{-1}\right)$ at $1000 \mathrm{hPa}$ over Israel. 
c)
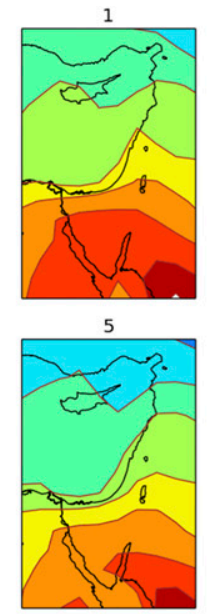

9

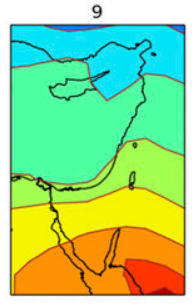

d)

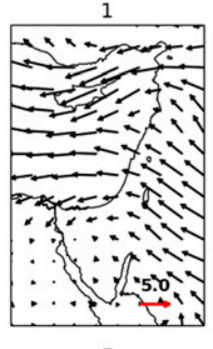

5

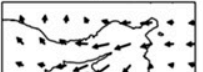

$\because 5=5: 5$

- $-2: \because 3$

Eニะー $\therefore \therefore$

pase $5: 1$

$12 x+2-2$

$\because:\left\{\frac{25.0}{20}\right.$

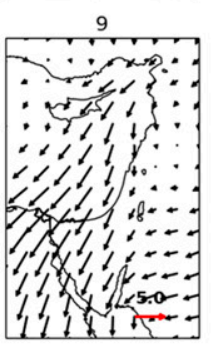

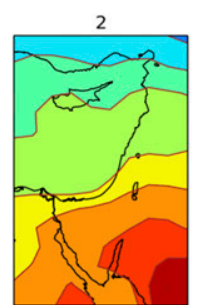

6

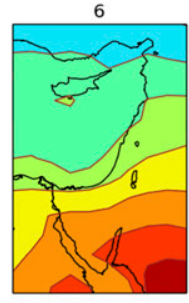

10
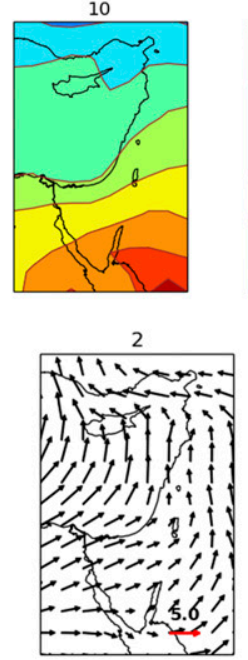

6

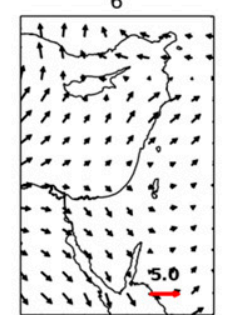

10

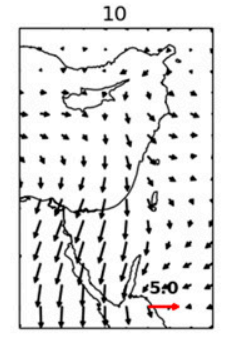

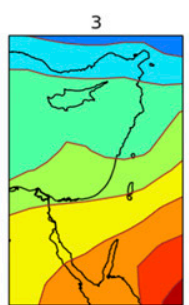

7
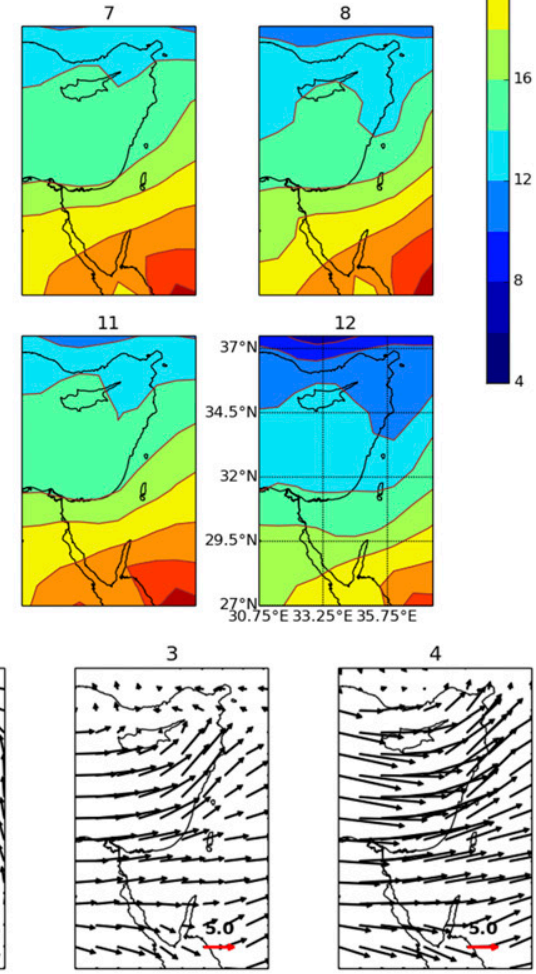

7

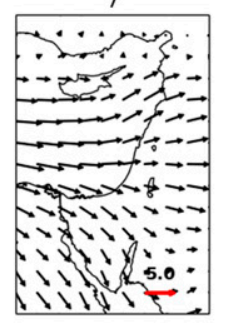

11
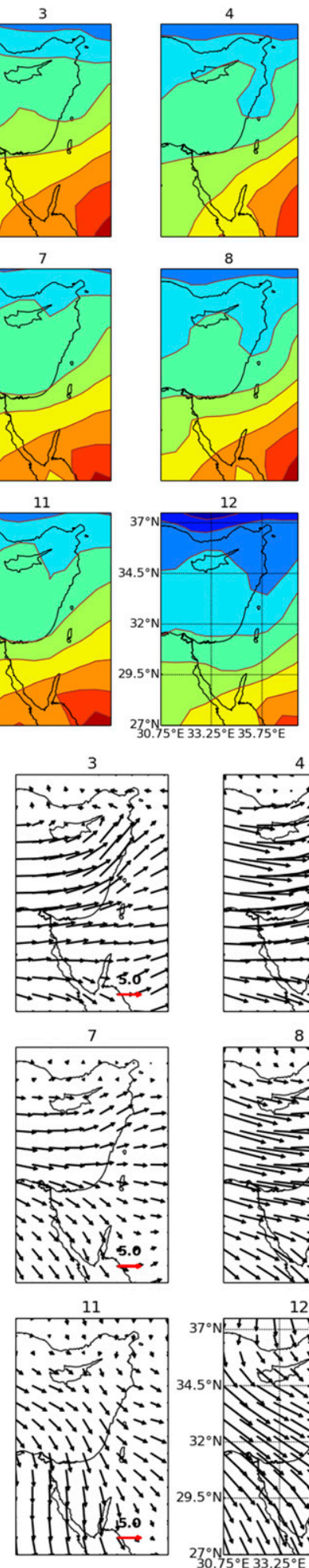

लक
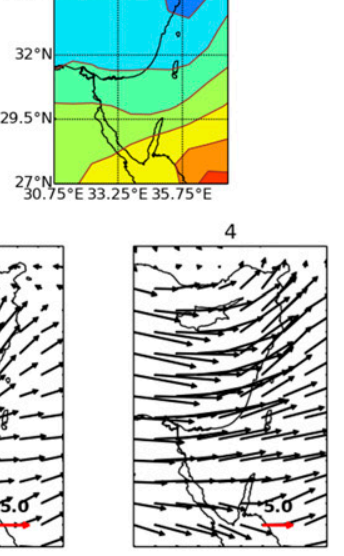

8
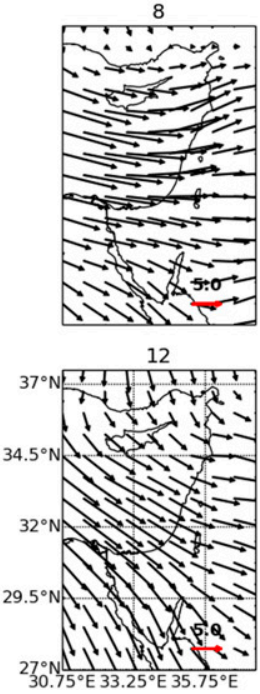

FIG. 5. (Continued) 

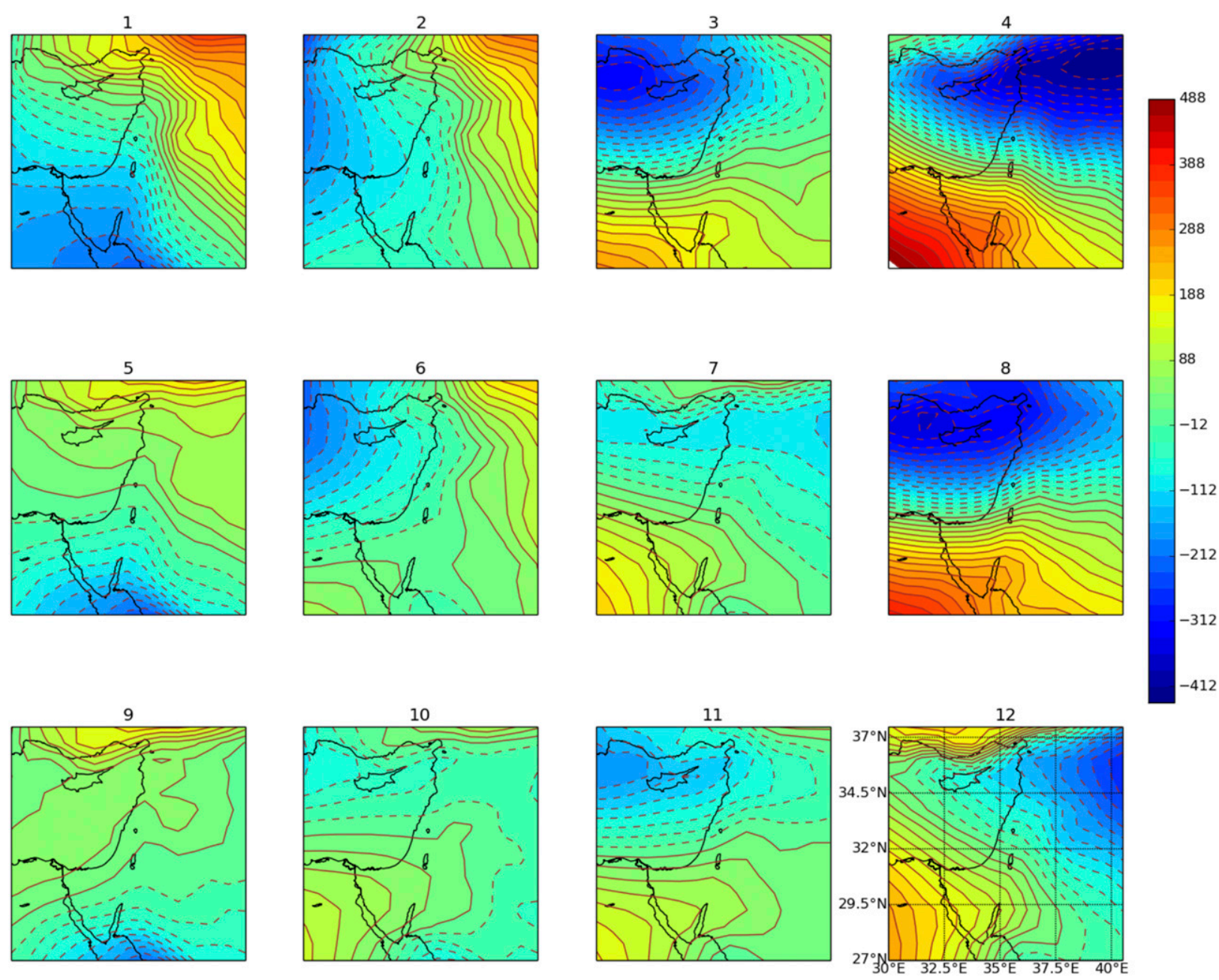

FIG. 6. The 0000 UTC DJF average geopotential height anomalies over the EM $\left(\mathrm{m}^{2} \mathrm{~s}^{-2}\right)$ at $925 \mathrm{hPa}$. The averages were calculated according to $4 \times 3 \mathrm{SOM}$ wind regimes (displayed in Fig. 4). The node number is shown at the top of each subfigure. The gap between neighboring isobars is $25 \mathrm{hPa}$. The RMSE over Israel is mostly $30-80 \mathrm{~m}^{2} \mathrm{~s}^{-2}$, with higher values of $55-115 \mathrm{~m}^{2} \mathrm{~s}^{-2}$ under deep lows (nodes 3 , 4,8 , and 12).

one to link the wind regimes at 0000 and 1200 UTC according to the similarity between their average ERA-Igp anomalies. The wind regimes at 1200 and 0000 UTC in Figs. 3 and 4 are ordered according to this resemblance. It is prominent that the regimes at 0000 UTC show a higher number of nodes with an eastern wind component versus 1200 UTC nodes with a western wind component (e.g., nodes 6 and 10 in Figs. 3 and 4). Higher similarity between average wind fields at 1200 and 0000 UTC is found under strong ERA-Igp anomalies (e.g., nodes 1 and 4 in Figs. 3 and 4). As a whole, the average wind speed at the 0000 UTC regimes is lower than the average wind speed at the 1200 UTC regimes.

Other ERA-Interim averages, according to specific humidity, temperature, and synoptic wind data, have shown high similarly between the 0000 and 1200 UTC results (Figs. 4b-d and online supplemental
Fig. S1). Therefore, average ERA-Interim fields at 1200 UTC will be presented and studied to link between local measured wind regimes and ERA-Interim data (synoptic-scale model with data assimilation). The relation between the synoptic parameters and the local wind at 0000 UTC will be summarized in section 4d. The ERA-Interim composites of temperature, humidity, and wind at 0000 UTC are included online as supplementary material in Fig. S1.

\section{c. Wind regimes and their relation to synoptic variables at 1200 UTC}

The averages of the synoptic variables according to ERA-Interim are presented in Figs. 5a-d, namely the average geopotential anomaly at $925 \mathrm{hPa}$ (Fig. 5a), average specific humidity at $925 \mathrm{hPa}$ (Fig. 5b), average temperature at $1000 \mathrm{hPa}$ (Fig. 5c), and average synoptic 
wind at $1000 \mathrm{hPa}$ (Fig. 5d). All averages were calculated according to $4 \times 3$ SOM 1200 UTC wind regimes (Fig. 3). At $1000 \mathrm{hPa}$, small average humidity differences were found among the various wind regimes because of the strong effect of the sea humidity. Significant differences were obtained at 850 and $925 \mathrm{hPa}$, however.

\section{1) CAtegory A: Western wind}

The strong western wind regimes relate to the location and pressure gradient of the lows (nodes 4, 8, and 12 in Figs. 3 and 5a). The average wind direction changes according to the movement of the lows from west to east; when the low is to the west of Israel, the wind is southwest. When the low is over Israel and to the east of Israel the wind direction is west and northwest, respectively (Ziv and Yair 1994). The movement of the lows is shown in Fig. 5a (nodes 3, 4, 8, 12, and 11). Along the Jordan and Arava Valleys, the steadiness is lower when the synoptic flow above the valley is perpendicular to the valley axis (Whiteman 2000; Carrera et al. 2009; nodes 8 and 12; Figs. 3 and 5d). At node 4, however, the steadiness along the valley increases as a result of enhanced synoptic wind speed (Figs. 3 and 5d).

The location and pressure gradient of lows are related to high humidity and low temperatures (Figs. 5b,c). Node 4 displays the highest humidity in accordance with the location of the strongest pressure gradients (Fig. 5a). At the north of Israel, low temperatures were obtained $\left(12^{\circ}-16^{\circ} \mathrm{C}\right)$ under winter lows (nodes 4,8 , and 12 ; Fig. $5 \mathrm{c}$ ). When the low moves farther to the east, the lowest temperatures, $10^{\circ}-14^{\circ} \mathrm{C}$, are obtained (node 12 ; Fig. 5c).

\section{2) CATEgory B: EAstern Wind}

Under $\mathrm{H}_{\mathrm{N}}$ or $\mathrm{H}_{\mathrm{E}}$, "polar outbreaks" carry cold dry air to Israel from Europe or Asia. Downslope wind over northern Israel is enhanced by gravity according to the relatively complex and steep topography around the Jezreel Valley, Hula Valley [situated to the north of the Sea of Galilee (Kinneret)] and the Sea of Galilee (Saaroni et al. 1996, 1998; Goldreich 2003). This description explains the low average temperatures $\left(14^{\circ}-18^{\circ}\right)$ and low average specific humidity $\left(\sim 40 \mathrm{dg} \mathrm{kg}^{-1}\right)$ obtained in the north of Israel at nodes 5 and 9 (Figs. 5b,c).

Hot and dry easterly winds under RST with high average temperatures $\left(18^{\circ}-22^{\circ} \mathrm{C}\right)$ and low humidity $\left(\sim 30 \mathrm{dg} \mathrm{kg}^{-1}\right)$ were obtained at node 1 (Figs. $\left.5 \mathrm{~b}, \mathrm{c}\right)$. This regime was previously described by Saaroni et al. (1998). The high situated to the north of the Red Sea trough induces easterly wind over Israel. Simultaneously, an upper-level ridge extends from the subtropical high (found according to ERA-Igp anomalies at $500 \mathrm{hPa}$; not shown), causing air subsidence. The combined effect of the continental tropical advection and the air subsidence creates hot and dry weather.

Berkovic (2016) studied the ability to use the semiobjective classification as a predictor of surface wind regimes over the central coastal plain. Later, in the same manner, a study was performed according to the data from the 53 IMS stations (not shown). The ability to separately define extreme easterly wind regimes was not found under surface wind averaging according to the frequent semiobjective classes [RST center $\left(\mathrm{RST}_{\mathrm{C}}\right), \mathrm{H}_{\mathrm{N}}$, and $\mathrm{H}_{\mathrm{E}}$. This absence stems from the fact that the semiobjective classes do not distinguish between weak and strong pressure gradients under the $\mathrm{H}$ and RST groups.

Under the strong wind regimes (A and B categories), good agreement is found between the average ERAInterim synoptic wind at 1000 and $925 \mathrm{hPa}$ and the surface wind regimes as a result of strong pressure gradients (e.g., Fig. 5d; nodes 1 and 5: east wind at the north of Israel; node 9: north wind along the coast; nodes 3 and 4: west-southwest wind over Israel; nodes 7 and 8: west wind over Israel; and nodes 11 and 12: northwest wind over Israel). This fact strengthens the validity of the local average surface wind regimes according to the measurement data.

\section{3) CATegory C: WeAK Wind}

Under this group, we were able to identify northerly and southerly regimes. Node 9 exhibits the effect of $\mathrm{H}_{\mathrm{N}}$ and RST (Figs. 5a,d and 2) on the surface flow. Northnorthwest winds are found along the central coastal plain while north-northeast winds are found along the north coastal plain. Node 2 exhibits south winds along the Judea and Samaria Mountains under a low to the west of Israel (Fig. 3). As the low approaches the area, the wind over the Judea and Samaria Mountains turns to the southwest (node 3 Fig. 3 ). Node 3 also shows southsouthwest winds along the coastal plain and south winds along the Jordan Valley resulting from the influence of the low to the west (Fig. 5a).

\section{$d$. Wind regimes and their relation to synoptic variables at 0000 UTC}

The average wind regimes at 0000 UTC were displayed in Fig. 4. As previously mentioned, the average ERA-Igp anomalies (Fig. 6), specific humidity, temperature, and wind (according to ERA-Interim data) at 1200 and 0000 UTC are similar (Figs. 5b,c and supplemental Fig. S1). This similarity facilitates the comparison between wind regimes during daytime and nighttime. Subtraction between composites at 0000 and 1200 UTC is not performed since separate SOM was applied at each hour. As in the previous 1200 UTC 
a)
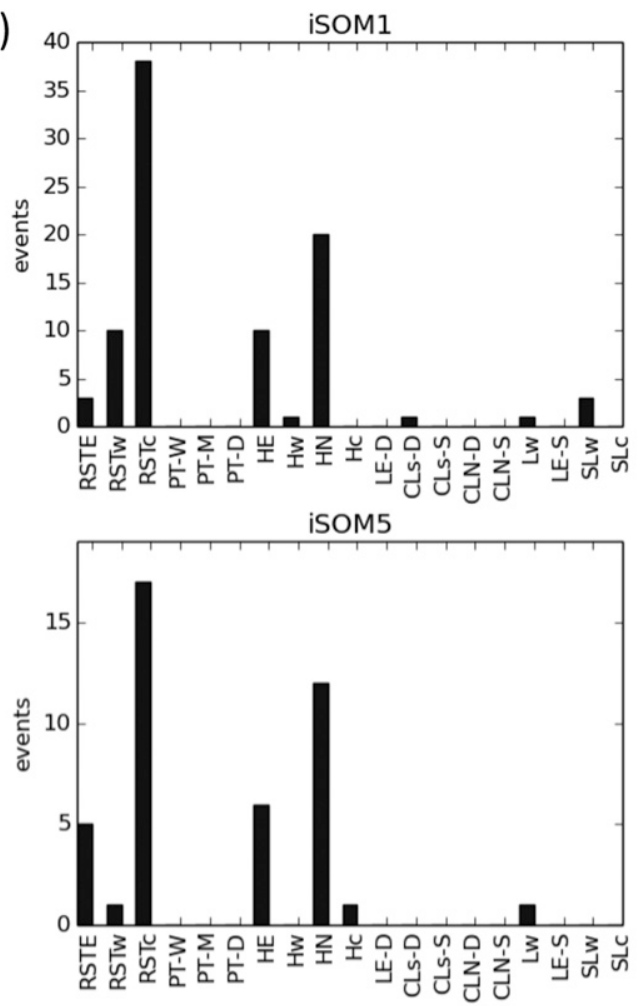

isom9

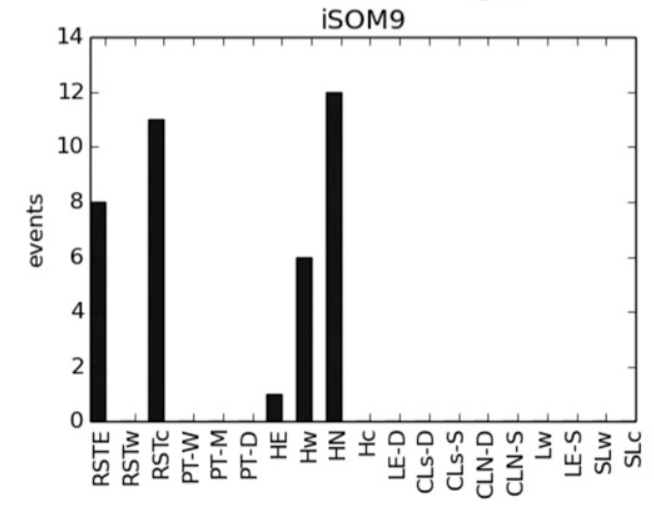

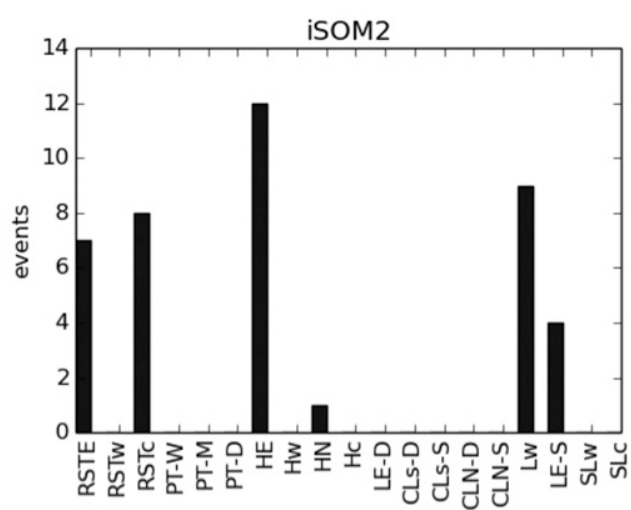

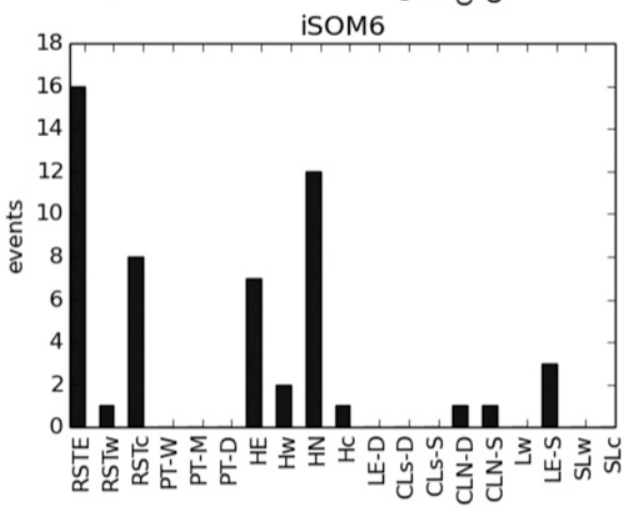

iSOM10

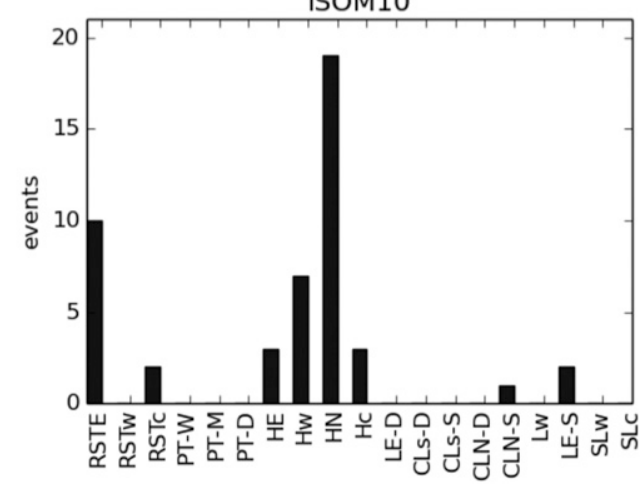

FIG. 7. The number of semiobjective synoptic class events at each of the 1200 UTC SOM wind regimes. (a) Regimes 1, 5, 9, 2, 6, and 10 mostly relate to RSTs, $H_{N}$, and $H_{E}$. (b) Regimes 3, 7, 11, 4, 8, and 12 mostly relate to lows and $\mathrm{H}_{\mathrm{W}}$. Regime 4 is mostly $\mathrm{CL}_{\mathrm{N}}-\mathrm{D}$, regimes 3 and 8 are deep and shallow lows, regime 7 is shallow lows, regime 12 is lows to the east, and regime 11 is a high to the west.

wind-regimes study (Figs. 3 and 5a), the effect of winter lows is found at nodes $3,4,8$, and 12 (Fig. 6). The effect of the winter highs and RST is evident at nodes $1,2,5$, and 9 at 0000 and 1200 UTC (Figs. 5a and 6).

\section{1) GRoup A: WeSTERN WIND}

The wind patterns at node 4 at 0000 and 1200 UTC are similar as a result of the stronger pressure gradient ( $-410 \mathrm{vs}-300 \mathrm{~m}^{2} \mathrm{~s}^{-2}$; node 4) (Fig. 6) suppressing the effect of the local wind. Along the Dead Sea and the northern part of the Arava Valley, south wind is prevalent in accordance with the local topography and the effect of the synoptic (ERA-Interim) southwest wind (supplemental Fig. S1c; node 4).

Under lows, the highest humidity and lowest temperatures were obtained. The highest humidity (60-70 $\left.\mathrm{dg} \mathrm{kg}^{-1}\right)$ was obtained at nodes $3,4,8$, and 12 (supplemental Fig. S1a). In the north of Israel, low temperatures are obtained $\left(14^{\circ}-16^{\circ} \mathrm{C}\right.$; nodes 4,8 , and 12) (Fig. 6). When the low moves farther to the east, the lowest temperatures, $11^{\circ}-13^{\circ} \mathrm{C}$, are obtained (Fig. 6 and supplemental Fig. S1b). These results are 
b)

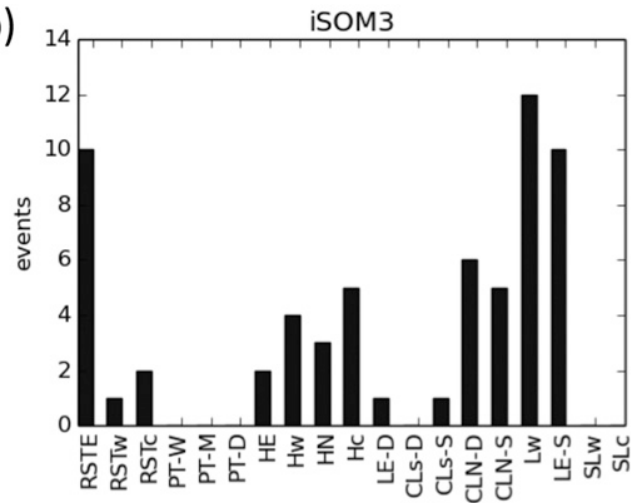

isom7

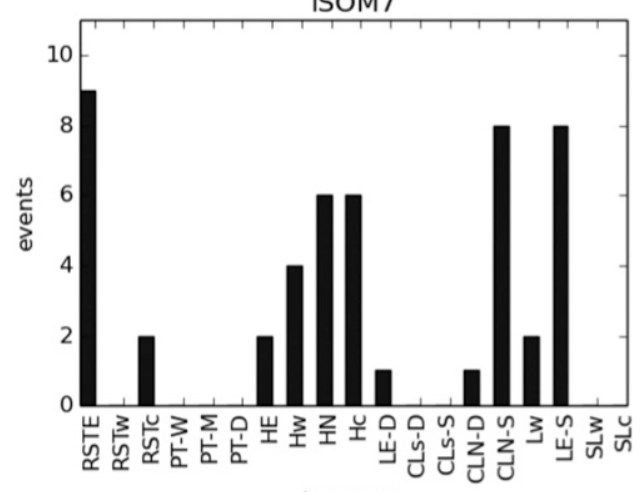

isom11

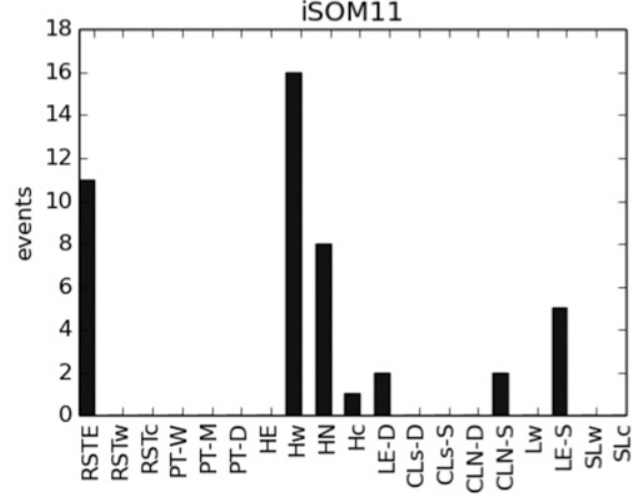

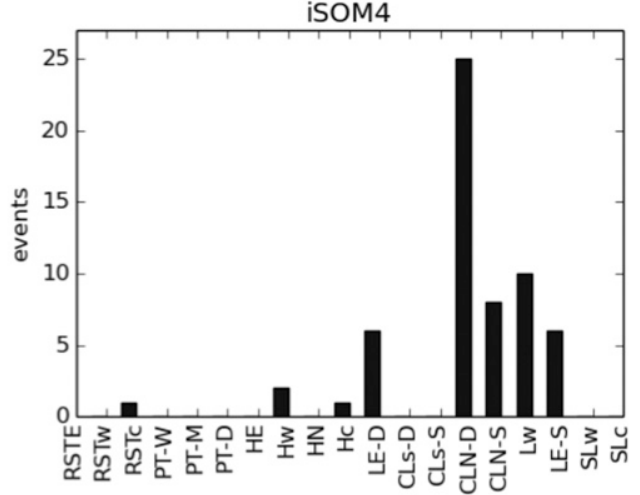

isOM8

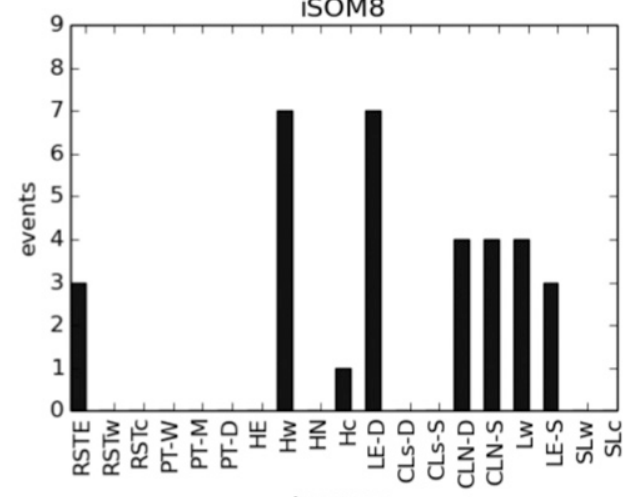

isom12

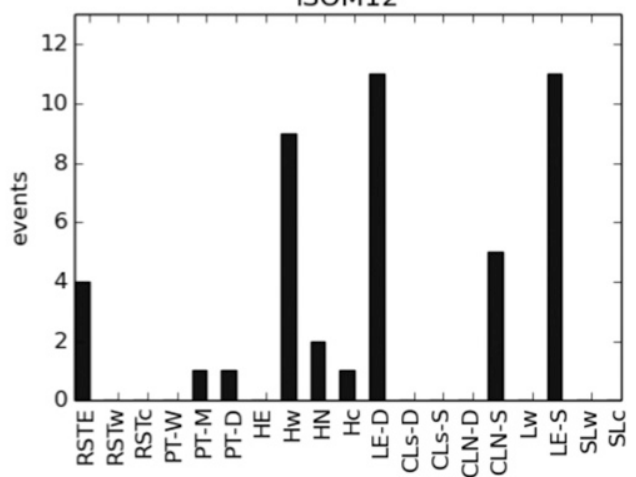

FIG. 7. (Continued)

in agreement with the previous 1200 UTC results (section $4 \mathrm{~b}$ ).

\section{2) GROUP B: EASTERN AND NORTHERN WINDS}

The wind patterns of nodes 1, 2, 5, and 9 (Figs. 3 and 4) at 0000 and 1200 UTC are similar as a result of strong synoptic pressure gradients (winter highs and RST; Figs. 5a and 6) and/or similarity between the isolines' shape dictating east-north synoptic winds (supplemental Fig. S1c). This direction is nearly parallel to the local nighttime wind direction. In a similar way, according to the semiobjective classification (Berkovic 2016) over the central coastal plain at 0000 UTC, east and southeast winds were found under $\mathrm{H}_{\mathrm{N}}, \mathrm{H}_{\mathrm{E}}$, and south and southwest winds were found under $\mathrm{CL}_{\mathrm{N}}-\mathrm{D}$ and $\mathrm{L}_{\mathrm{E}}-\mathrm{D}$. The lowest average humidity, $31-42 \mathrm{dg} \mathrm{kg}^{-1}$, was obtained at nodes 1 and 5 (supplemental Fig. S1a). The highest average temperatures, $15^{\circ}-21^{\circ} \mathrm{C}$, were obtained at nodes 1 and 2 (supplemental Fig. S1b). These results are in agreement with the previous description of the easterly wind regimes in section $4 \mathrm{~b}$.

\section{e. A comparison between the semiobjective and SOM classifications at 1200 UTC}

To find the link between the semiobjective classification and the SOM classification, statistics of events according to the two classifications were obtained. Each 1200 UTC event is classified twice: first according to the 
SOM 1200 UTC data analysis and second according to Alpert et al's (2004) semiobjective classification. The relation between these classifications was found by counting the number of events of each semiobjective synoptic class under each SOM regime. The results are displayed in Fig. 7. The figures agree with the above description of the wind regimes and their relation to synoptic parameters. There is a clear separation between nodes with major contributions from RSTs, $\mathrm{H}_{\mathrm{N}}$, and $\mathrm{H}_{\mathrm{E}}$ (Fig. 7a) against nodes with major contributions from lows or $\mathrm{H}_{\mathrm{W}}$ (Fig. 7b). The largest contributions of the semiobjective classes at each node are summarized in Table 2.

There is no clear division among the various classes in accordance with previous work presenting similar average wind field under various synoptic classes (Berkovic 2016) and the fact that semiobjective classes are sometimes similar and may be categorized under more than one synoptic class (Osetinsky 2006; Dayan et al. 2012). The wind regimes relate to the pressure gradients rather than to the specific synoptic class; the distinction between weak and strong pressure gradients is relevant under all synoptic groups. The semiobjective classification only refers to deep and shallow lows.

\section{f. Transition probabilities and persistence}

The probability to switch from one wind regime at 0000 or $1200 \mathrm{UTC}$ to another regime $12 \mathrm{~h}$ later is calculated from the statistics of the events. The transition probability between two consecutive regimes is defined as the number of observed transitions from the earlier regime to the later regime divided by the total number of events of the earlier regime. These probabilities are displayed in Figs. 8 a and 8 b. There are 12 possible transitions from one regime to the next; hence, $(1 / 12) \times 100 \%$ is the random probability. Accordingly, probabilities lower than $10 \%$ are considered insignificant and were not included. High probabilities of staying in similar regimes relate to low variability and vice versa. Regimes with easterly wind at the north of Israel under RST and $\mathrm{H}_{\mathrm{N}}$ show the highest frequency and persistence $(62 \%$ transition probability from regime 1 at 1200 UTC to regime 1 at 0000 UTC and from regime 1 at 0000 UTC to regime 1 at 1200 UTC). Deep lows (regime 4 at 1200 UTC) also have high persistence as expected. The transition probability from regime 4 at $1200 \mathrm{UTC}$ (mostly $\mathrm{CL}_{\mathrm{N}}-\mathrm{D}$ ) to regime 4 at $0000 \mathrm{UTC}$ is $45 \%$. The transition probabilities from regime 4 at 0000 UTC (low mainly to the east) to regimes 4,8 , and 12 at 1200 UTC (winter lows moving farther to the east) are $19 \%, 26 \%$, and $35 \%$, respectively. According to Osetinsky (2006), Red Sea troughs are unchangeable up to 6 days and winter lows stay 1-4 days.

On the other hand, regimes such as 3,6, and 7 at 1200 UTC show relatively low probabilities of $\sim 20 \%$ and
TABLE 2. The major contributing semiobjective classes at each of the 1200 UTC wind regimes.

\begin{tabular}{cll}
\hline \hline SOM node & Major semiobjective classes & \\
\hline 1 & RST $_{\mathrm{C}}$ and $\mathrm{H}_{\mathrm{N}}$ & \\
5 & $\mathrm{RST}_{\mathrm{C}}$ and $\mathrm{H}_{\mathrm{N}}$ & \\
9 & $\mathrm{RST}_{\mathrm{E}}, \mathrm{RST}_{\mathrm{C}}$, and $\mathrm{H}_{\mathrm{N}}$ & \\
2 & $\mathrm{RST}_{\mathrm{C}}, \mathrm{RST}_{\mathrm{E}}, \mathrm{H}_{\mathrm{E}}$, and $\mathrm{L}_{\mathrm{W}}$ & \\
6 & $\mathrm{RST}_{\mathrm{E}}$ and $\mathrm{H}_{\mathrm{N}}$ & \\
10 & $\mathrm{RST}_{\mathrm{E}}$ and $\mathrm{H}_{\mathrm{N}}$ & \\
3 & $\mathrm{RST}_{\mathrm{E}}, \mathrm{L}_{\mathrm{W}}$, and $\mathrm{L}_{\mathrm{E}}-\mathrm{S}$ & Arrival of lows from \\
& & \\
7 & $\mathrm{RST}_{\mathrm{E}}, \mathrm{CL}_{\mathrm{N}}-\mathrm{S}$, and $\mathrm{L}_{\mathrm{E}}-\mathrm{S}$ & \\
11 & $\mathrm{RST}_{\mathrm{E}}$ and $\mathrm{H}_{\mathrm{W}}$ & \\
4 & $\mathrm{CL}_{\mathrm{N}}-\mathrm{D}$ & the west \\
8 & $\mathrm{~L}_{\mathrm{E}}-\mathrm{D}$ and $\mathrm{H}_{\mathrm{W}}$ & Low moved to the east \\
12 & $\mathrm{~L}_{\mathrm{E}}-\mathrm{S}$ and $\mathrm{L}_{\mathrm{E}}-\mathrm{D}$ & \\
& &
\end{tabular}

therefore higher diurnal variability. It is noticeable, however, that transitions are among similar synoptic classes. For example, regime 3 at 1200 UTC (under a shallow low to the west and high to the west) evolves to regimes 7,8 , and 12 at 0000 UTC with a shallow low to the west, a shallow high to the west, and a deep low to the west, respectively. These wind regimes refer to the synoptic classes $\mathrm{L}_{\mathrm{W}}, \mathrm{L}_{\mathrm{E}}-\mathrm{S}, \mathrm{RST}_{\mathrm{E}}$, and $\mathrm{CL}_{\mathrm{N}}-\mathrm{S}$ (Table 2), which stay (Osetinsky 2006) respectively 1-4 days, 1-6 days, unchangeable up to 6 days, and 1-6 days. Weak and variable winds are mostly determined by local effects and therefore experience the highest diurnal variability; the daily persistence according to the synoptic classes may be high, however.

The duration in days of 1200 UTC regimes was sorted according to the number of consecutive days. The frequency of each wind regime as a function of duration $(1,2, \ldots, 5$ days $)$ is shown in Fig. 9. The persistence at the various regimes is in accordance with Figs. $8 \mathrm{a}$ and $8 \mathrm{~b}$. Regime $1\left(\mathrm{RST}_{\mathrm{C}}\right.$ and $\left.\mathrm{H}_{\mathrm{N}}\right)$ stays 1-6 days, regimes 3 and 8 (lows) stay 1-5 days, and regimes 6 and 11 stay 1-2 days and have the highest number of single-day events. Regime 11 , unlike regime 6 , does not display weak winds (Fig. 3). Therefore, a weak wind regime is not necessarily related to low daily persistence.

The daily persistence of the wind regimes at the other synoptic hours gave similar results. The highest persistence is achieved for wind regime 1 at 1200 UTC (and its most similar wind regimes at the other synoptic hours), related mostly to $\mathrm{H}_{N}$ and $\mathrm{RST}_{\mathrm{C}}$.

\section{Summary and conclusions}

SOM analysis of surface wind measurements including all of the synoptic hours during the winter months (December, January, and February) was 
a)

\begin{tabular}{|c|c|c|c|c|c|c|c|c|c|c|c|c|}
\hline $12 Z->0 Z$ & $1 \mathrm{E}$ & $2 \mathrm{E}$ & $3 \mathrm{~W}$ & $4 \mathrm{~W}$ & $5 \mathrm{E}$ & $6 \mathrm{wE}$ & $7 w$ & $8 \mathrm{~S}+\mathrm{W}$ & $9 \mathrm{E}$ & $10 \mathrm{wE}$ & $11 \mathrm{wE}$ & $12 \mathrm{SE}+\mathrm{SW}$ \\
\hline $1 \mathrm{E}$ & 62 & & & & & & & & & & & \\
\hline $2 \mathrm{wE}$ & & & & & & 22 & & & & & 20 & 27 \\
\hline $3 \mathrm{~W}$ & & & & & & & 14 & 18 & & & & 23 \\
\hline 4 WSW & & & & 45 & & & & 18 & & & & 13 \\
\hline $5 \mathrm{E}$ & 47 & 16 & & & 25 & & & & & & & \\
\hline $6 w$ & & & & & 20 & 24 & & & & 12 & 14 & \\
\hline $7 \mathrm{~W}$ & & & & & & & & & 18 & 18 & 22 & 18 \\
\hline $8 \mathrm{~W}$ & & & 12 & 29 & & & & & & & 21 & \\
\hline $9 \mathrm{~N}$ & 26 & & & & 34 & & & & 19 & & & \\
\hline $10 \mathrm{~W} N W$ & & & & & & & & & 40 & 17 & 12 & \\
\hline $11 \mathrm{NW}$ & & & & & & & & & 28 & 30 & 16 & \\
\hline $12 \mathrm{~W}$ & & & 16 & 13 & & & 13 & & & 25 & & 11 \\
\hline
\end{tabular}

b)

\begin{tabular}{|c|c|c|c|c|c|c|c|c|c|c|c|c|}
\hline $0 Z->12 Z$ & $1 \mathrm{E}$ & $2 \mathrm{wE}$ & $3 \mathrm{~W}$ & 4 WSW & $5 \mathrm{E}$ & $6 w$ & $7 \mathrm{~W}$ & $8 \mathrm{~W}$ & $9 \mathrm{~N}$ & $10 \mathrm{w}$ NW & $11 \mathrm{NW}$ & $12 \mathrm{~W}$ \\
\hline $1 \mathrm{E}$ & 62 & 17 & & & & & & & & & & \\
\hline $2 \mathrm{E}$ & & 14 & 11 & & 11 & 14 & 14 & & 11 & & & \\
\hline $3 \mathrm{~W}$ & & & & & & & 16 & & & & 26 & 33 \\
\hline $4 \mathrm{~W}$ & & & & 19 & & & & 26 & & & & 35 \\
\hline $5 \mathrm{E}$ & 32 & & & & 22 & & & & 14 & & & \\
\hline $6 \mathrm{wE}$ & & 17 & 21 & & & & & & & & 12 & \\
\hline $7 w$ & & & 11 & 11 & & 14 & 26 & & & & 17 & \\
\hline $8 \mathrm{~S}+\mathrm{W}$ & & & 26 & 36 & & & & 30 & & & & \\
\hline $9 \mathrm{E}$ & 12 & & & & 14 & & & & 39 & 14 & 12 & \\
\hline $10 w E$ & & & & & & 18 & & & & 18 & 20 & \\
\hline $11 w E$ & & & 17 & 13 & & 17 & 19 & & & & & \\
\hline $12 \mathrm{SE}+\mathrm{SW}$ & & & 24 & 29 & & & & & & & & 13 \\
\hline
\end{tabular}

FIG. 8. (a) Transition probabilities (\%) from 1200 UTC regimes (indicated by row number) to 0000 UTC regimes (at the top of each column). (b) Transition probabilities (\%) from 0000 UTC regimes (indicated by row number) to 1200 UTC regimes (at the top of each column). The main wind directions of each regime are indicated next to the regime number, with "w" indicating weak winds. Transitions with probabilities of lower than $10 \%$ were omitted.

conducted to investigate the wind regimes at the synoptic hours over Israel. Accordingly, a $5 \times 3$ map with a nonhomogeneous distribution of events was found because of the strong effect of the diurnal heating on the surface winds, even during winter. Consequently, a separate SOM analysis at each synoptic hour was performed. Similar conclusions were found according to the two analyses. A full comparison of these results is beyond the scope of this paper and will be studied in the future. We present the 0000 and 1200 UTC $4 \times 3$ maps to show the typical surface wind regimes at daytime and nighttime. The ability to reconstruct previous knowledge by an objective automatic algorithm is demonstrated. The conclusions of this work are in agreement with previous subjective studies ( $\mathrm{Ziv}$ and Yair 1994; Saaroni et al. 1998; Goldreich 2003) and results from quantitative characterization according to the semiobjective classification (Berkovic 2016). The ability to automatically and objectively define wind regimes at any hour of the day, without the need to rely on the subjective or semiobjective synoptic classifications (which are limited only to 1200 UTC), set the groundwork for future applications such as quantification of the quality of mesomodel climatological predictions on the basis of SOM classification (Jolly et al. 2016) or relating local flow and patterns of air pollution (Beaver and Palazoglu 2006; Carreón-Sierra et al. 2015).

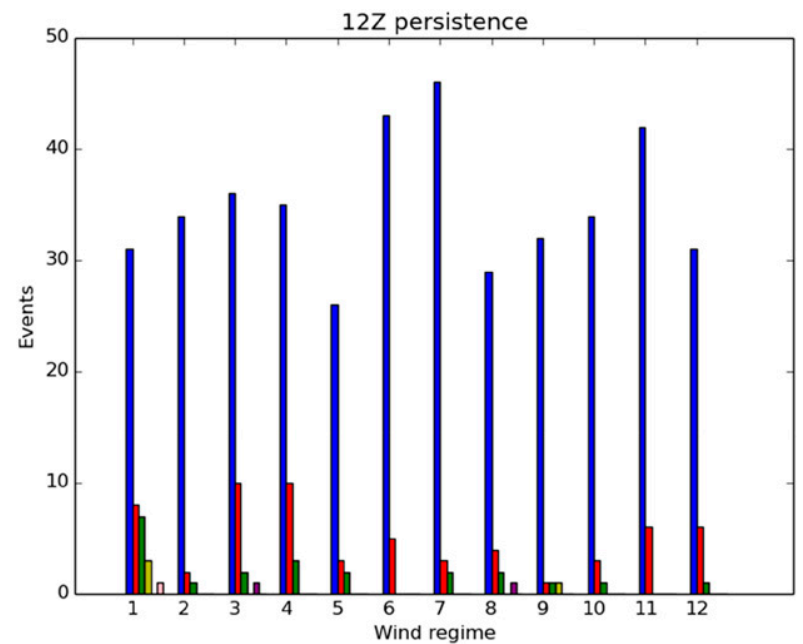

FIG. 9. Daily persistence of 1200 UTC wind regimes. Blue: 1 day, red: 2 days, green: 3 days, light green: 4 days, purple: 5 days, and pink: 6 days. 
SOM are flexible, and there are many possibilities to analyze the data. Since the motivation was to characterize wind regimes at a 6-hourly resolution, the SOM analysis was performed separately at each synoptic hour. This way, the maximum possible patterns were obtained at each synoptic hour with the highest possible steadiness at most of the wind regimes. The relation between synoptic data and wind regime was found by composite calculation.

The synoptic geopotential anomalies according to the SOM classification show the relation between synoptic classes and wind regimes. There is correspondence between the wind regimes at 1200 UTC and the semiobjective groups. Three main groups of wind regimes relate respectively to highs and RSTs, winter lows, and shallow synoptic classes. Wind regimes under weak ERA-Igp anomalies present relatively low speed and steadiness. Their diurnal variability is according to radiation and orography. They do not necessarily exhibit the lowest daily persistence since the persistence is according to the prevalent synoptic class. Wind regimes under strong ERA-Igp anomalies show less diurnal variability (12-24-h time scale) because of stronger synoptic effects as the ERA-Igp anomalies strengthen.

The wind regimes relate to the pressure gradient depth rather than to the specific semiobjective synoptic class. While the semiobjective classification refers only to the depth of the winter lows, the SOM classification identifies extreme wind regimes under lows as well as highs and/or RSTs. Unlike SOM, during daytime, the semiobjective classification reveals only strong westerly wind regimes under winter lows. Berkovic (2016) has shown that more than one semiobjective synoptic class generates similar wind patterns. SOM eliminates duplications and enables specific characterization of each wind regime. Furthermore, it suggests a synoptic classification that stresses the depth of the pressure gradients rather than the exact shape of the isobars. The semiobjective classification has ambiguities (Dayan et al. 2012) that are eliminated when applying SOM. SOM classification demands training, however, including trial-and-error search, to find the best way to sort the data according to the research question. A rectangular $N \times M$ SOM map is recommended. Prior knowledge regarding the studied data is also necessary.

Wind regimes are affected by the local orography. This study inspected 53 stations at various areas with varying orography. Under certain wind regimes, it was shown that the steadiness is high over certain areas and low at others (e.g., coastal plain vs Jordan Valley). This fact suggests performing a separate study of wind regimes for local areas according to orography. The characterization of wind regimes at specific areas may enhance the local wind field steadiness and may reduce the number of dominant wind regimes. This study may also be extended to classify wind regimes during the transitional seasons (SON and MAM) and for the whole year excluding summer (JJA).

Acknowledgments. The author thanks Prof. Pinhas Alpert, Prof. Hadas Saaroni, Dr. Isabela Osetinsky, and Dr. Baruch Ziv for providing the synoptic classification data. Special thanks are given to Prof. Alpert for his hospitality during the author's sabbatical leave at Tel Aviv University in 2016. The author also thanks the anonymous reviewer of her 2016 paper who recommended the application of SOM to define wind or synoptic regimes and who carefully read the manuscript. Many thanks are given also to Dr. Ziv Klausner for fruitful discussions.

\section{REFERENCES}

Alpert, P., I. Osetinsky, B. Ziv, and H. Shafir, 2004: Semi-objective classification for daily synoptic systems: Application to the eastern Mediterranean climate change. Int. J. Climatol., 24, 1001-1011, doi:10.1002/joc.1036.

Beaver, S., and A. Palazoglu, 2006: Cluster analysis of hourly wind measurements to reveal synoptic regimes affecting air quality. J. Appl. Meteor. Climatol., 45, 1710-1726, doi:10.1175/ JAM2437.1.

Berkovic, S., 2016: Synoptic classes as a predictor of hourly surface wind regimes: The case of the central and southern Israeli coastal plains. J. Appl. Meteor. Climatol., 55, 1533-1547, doi:10.1175/JAMC-D-16-0093.1.

Berrisford, P., and Coauthors, 2011: The ERA-Interim archive version 2.0. ECMWF ERA Rep. 1, 23 pp., http://www.ecmwf. int/en/elibrary/8174-era-interim-archive-version-20.

Bitan, A., 1977: The influence of the special shape of the Dead-Sea and its environment on the local wind system. Theor. Appl. Climatol., 24, 283-301, doi:10.1007/BF02263460.

Carreón-Sierra, S., A. Salcido, T. Castro, and A.-T. CeladaMurillo, 2015: Cluster analysis of the wind events and seasonal wind circulation patterns in the Mexico City region. Atmosphere, 6, 1006-1031, doi:10.3390/atmos6081006.

Carrera, M. L., J. R. Gyakum, and C. A. Lin, 2009: Observational study of wind channeling within the St. Lawrence River valley. J. Appl. Meteor. Climatol., 48, 2341-2361, doi:10.1175/ 2009JAMC2061.1.

Dayan, U., and I. Levy, 2002: Relationship between synoptic-scale atmospheric circulation and ozone concentrations over Israel. J. Geophys. Res., 107, 4813, doi:10.1029/2002JD002147.

— A. Tubi, and I. Levy, 2012: On the importance of synoptic classification methods with respect to environmental phenomena. Int. J. Climatol., 32, 681-694, doi:10.1002/joc.2297.

Goldreich, Y., 2003: The Climate of Israel: Observation, Research and Application. Springer, $298 \mathrm{pp}$.

Guèye, A. K., S. Janicot, A. Niang, S. Sawadogo, B. Sultan, A. Diongue-Niang, and S. Thiria, 2011: Weather regimes over Senegal during the summer monsoon season using selforganizing maps and hierarchical ascendant classification. Part I: Synoptic time scale. Climate Dyn., 36, 1-18, doi:10.1007/ s00382-010-0782-6. 
Gutierrez, J. M., R. Cano, A. S. Cofino, and C. Sordo, 2005: Analysis and downscaling multi-model seasonal forecasts in Peru using self-organizing maps. Tellus, 57A, 435-447, doi:10.3402/tellusa.v57i3.14672.

Hewitson, B. C., and R. G. Crane, 2002: Self-organizing maps: Applications to synoptic climatology. Climate Res., 22, 13-26, doi:10.3354/cr022013.

Ismail, S., A. Shabri, and R. Samsudin, 2011: A hybrid model of self-organizing maps (SOM) and least square support vector machine (LSSVM) for time-series forecasting. Expert Syst. Appl., 38, 10 574-10 578, doi:10.1016/j.eswa.2011.02.107.

Jolly, B., and Coauthors, 2016: A validation of the Antarctic Mesoscale Prediction System using self-organizing maps and high-density observations from SNOWWEB. Mon. Wea. Rev. 144, 3181-3200, doi:10.1175/MWR-D-15-0447.1.

Kalinić, H., F. Matić, H. Mihanović, I. Vilibić, N. Žagar, B. Jasenko, and M. Tudor, 2015: Comparison of two meteorological models using self-organizing maps. OCEANS 2015-Genova, Genoa, Italy, Institute of Electrical and Electronics Engineers Oceanic Engineering Society and Marine Technology Society, 7271374, doi:10.1109/OCEANS-Genova.2015.7271374.

Kohonen, T., 2001: Self-Organizing Maps. 3rd ed. Springer, 501 pp.

_ - J. Hynninen, J. Kanagas, and J. Laaksonen, 1996: SOM_PAK: The Self-Organizing Map Program Package. Helsinki University of Technology Laboratory of Computer and Information Science Rep. A31, 27 pp.

Levy, I., U. Dayan, and Y. Mahrer, 2008: A five-year study of coastal recirculation and its effect on air pollutants over the east Mediterranean region. J. Geophys. Res., 113, D16121, doi:10.1029/2007JD009529.

$\longrightarrow, \ldots$, and -2010 : Differing atmospheric scales of motion and their impact on air pollutants. Int. J. Climatol., 30, 612-619, doi:10.1002/joc.1905.

Liu, Y., and R. H. Weisberg, 2011: A review of self-organizing map applications in meteorology and oceanography. Self Organizing Maps: Applications and Novel Algorithm Design, J. I. Mwasiagi, Ed., InTech, 253-272, https://www.intechopen.com/books/ self-organizing-maps-applications-and-novel-algorithm-design/ a-review-of-self-organizing-map-applications-in-meteorology-andoceanography.

,-- , and C. N. K. Mooers, 2006: Performance evaluation of the self-organizing map for feature extraction. J. Geophys. Res., 111, C05018, doi:10.1029/2006JA011890.

—, Y. Liu, W. Y. Y. Cheng, and G. Roux, 2010: Statistical characteristics of winds at Xcel wind farms. Presentation, Wind Energy Prediction Research and Development Workshop, Boulder, Colorado, University Corporation for Atmospheric Research, 22 pp., http://ral.ucar.edu/projects/ wind_energy_workshop/presentations/Statistical_Characteristics_ of_Winds_YLiu_15.pdf.

Mihanović, H., S. Cosoli, I. Vilibić, D. Ivanković, V. Dadić, and M. Gačić, 2011: Surface current patterns in the northern
Adriatic extracted from high-frequency radar data using self-organizing map analysis. J. Geophys. Res., 116, C08033, doi:10.1029/2011JC007104.

Nigro, M. A., and J. J. Cassano, 2014: Identification of surface wind patterns over the Ross Ice Shelf, Antarctica, using selforganizing maps. Mon. Wea. Rev., 142, 2361-2378, doi:10.1175/MWR-D-13-00382.1.

Osetinsky, I., 2006: Climate changes over the E. MediterraneanA synoptic systems classification approach. Ph.D. thesis, Tel Aviv University, 153 pp., http://primage.tau.ac.il/libraries/ theses/exeng/free/2079562.pdf.

Reusch, D., R. B. Alley, and B. C. Hewitson, 2011: Relative performance of self-organizing maps and principal component analysis in pattern extraction from synthetic climatological data. Polar Geogr., 29, 188-212, doi:10.1080/ 789610199.

Richardson, A. J., C. Risien, and F. A. Shillington, 2003: Using selforganizing maps to identify patterns in satellite imagery. Prog. Oceanogr., 59, 223-239, doi:10.1016/j.pocean.2003.07.006.

Saaroni, H., A. Bitan, P. Alpert, and B. Ziv, 1996: Continental polar outbreaks into the Levant and eastern Mediterranean. Int. J. Climatol., 16, 1175-1191, doi:10.1002/ (SICI)1097-0088(199610)16:10<1175::AID-JOC79>3.0.CO;2-\#. , B. Ziv, A. Bitan, and P. Alpert, 1998: Easterly wind storms over Israel. Theor. Appl. Climatol., 59, 61-77, doi:10.1007/ s007040050013.

Samad, T., and S. A. Harp, 1992: Self organization with partial data. Network, 3, 205-212, doi:10.1088/0954-898X_3_2_008.

Sang, H., A. E. Gelfand, C. Lennard, G. Hegerl, and B. Hewitson, 2008: Interpreting self-organizing maps through space-time data models. Ann. Appl. Stat., 2, 1194-1216, doi:10.1214/ 08-AOAS174.

Seefeldt, M. W., and J. J. Cassano, 2012: A description of the Ross Ice Shelf air stream (RAS) through the use of self-organizing maps (SOM). J. Geophys. Res., 117, D09112, doi:10.1029/ 2011JD016857.

Sheridan, S. C., and C. C. Lee, 2011: The self-organizing map in synoptic climatological research. Prog. Phys. Geogr., 35, 109-119, doi:10.1177/0309133310397582.

Sideratos, G., and N. D. Hatziargyriou, 2007: An advanced statistical method for wind power forecasting. IEEE Trans. Power Syst., 22, 258-265, doi:10.1109/TPWRS.2006.889078.

Skibin, D., and A. Hod, 1979: Subjective analysis of mesoscale flow patterns in northern Israel. J. Appl. Meteor., 18, 329-338, doi:10.1175/1520-0450(1979)018<0329:SAOMFP $>2.0 . C O ; 2$.

Whiteman, C. D., 2000: Mountain Meteorology: Fundamentals and Applications. Oxford University Press, $355 \mathrm{pp}$.

Ziv, B., and Y. Yair, 1994: An Introduction to Meteorology (in Hebrew). Open University of Israel, 411 pp.

- H. Saaroni, and P. Alpert, 2004: The factors governing the summer regime of the eastern Mediterranean. Int. J. Climatol., 24, 1859-1871, doi:10.1002/joc.1113. 